NOTICE: This is the author's version of a work that was accepted for publication in International Journal of Machine Tools and Manufacture. Changes resulting from the publishing process, such as peer review, editing, corrections, structural formatting, and other quality control mechanisms may not be reflected in this document.

Changes may have been made to this work since it was submitted for publication. A definitive version was subsequently published in International Journal of Machine Tools and Manufacture, Vol. 86 (2014).

http://doi.org/10.1016/j.ijmachtools.2014.07.003 
Manufacture

Elsevier Editorial System(tm) for International Journal of Machine Tools and

Manuscript Draft

Manuscript Number:

Title: Developments in the non-traditional machining of particle reinforced metal matrix composites

Article Type: Review Article

Keywords: Particle reinforced metal matrix composites, non-traditional machining, material removal rate, surface finish, machining mechanism.

Corresponding Author: Dr. Alokesh Pramanik, PhD

Corresponding Author's Institution: Curtin University

First Author: Alokesh Pramanik, PhD

Order of Authors: Alokesh Pramanik, PhD

Abstract: The non-traditional machining of particulate reinforced metal matrix composites is relatively new. However, researchers seem to pay more attention in this field recently as the traditional machining of particulate reinforced metal matrix composites is very complex. This research investigates different non-traditional machining, such as electro-discharge, laser beam, abrasive water jet, electro-chemical and electro-chemical discharge machining of this composite materials. The machining mechanism, material removal rate/machining speed and surface finish have been analysed for every machining process. This analysis clearly shows that vaporisation, melting, chemical dissolution and mechanical erosion are the main material removal mechanism during non-traditional machining. The thermal degradation and presence of reinforcement particles mainly damage the machined surface. The understanding on electro-discharge, laser beam and abrasive water jet machining are more developed than that of electro-chemical and electro-chemical discharge machining for particulate reinforced MMC. 


\title{
Developments in the non-traditional machining of particle reinforced metal matrix composites
}

\begin{abstract}
The non-traditional machining of particulate reinforced metal matrix composites is relatively new. However, researchers seem to pay more attention in this field recently as the traditional machining of particulate reinforced metal matrix composites is very complex. This research investigates different non-traditional machining, such as electro-discharge, laser beam, abrasive water jet, electro-chemical and electro-chemical discharge machining of this composite materials. The machining mechanism, material removal rate/machining speed and surface finish have been analysed for every machining process. This analysis clearly shows that vaporisation, melting, chemical dissolution and mechanical erosion are the main material removal mechanism during non-traditional machining. The thermal degradation and presence of reinforcement particles mainly damage the machined surface. The understanding on electro-discharge, laser beam and abrasive water jet machining are more developed than that of electro-chemical and electro-chemical discharge machining for particulate reinforced MMC.
\end{abstract}

Key words: Particle reinforced metal matrix composites, non-traditional machining, material removal rate, surface finish, machining mechanism.

\section{Introduction}

The use of traditional machinery to machine metal matrix composite causes serious tool wear due to the abrasive nature of reinforcing particles which shortens the tool life (Pramanik, Zhang et al. 2006). In addition, the worse surface finish due to tool-particle-machined surface interactions in conventional machining significantly hinder the use of MMCs (Pramanik, Zhang et al. 2007). Electronic-grade MMCs of high reinforcement content are nearly impossible to machine by conventional methods. Thus non-conventional techniques, including electro-discharge, laser-beam, electro-chemical and abrasive water jet machining have also been applied to these materials (Hihara 2000). However, the research in machining of MMCs in traditional ways has been given higher importance over the non-traditional machining for the last few decades. Thus, there is little advancement in understanding of non-traditional machining of MMCs. There are some studies in the 
field of non-traditional machining of MMCs which produce interesting results as well. Different nontraditional machining methods of MMCs has its own advantages and drawbacks though these have higher potential over the tradition methods as the overall understanding on the suitability of this methods for MMC is relatively low. A clear understanding of these non-traditional methods for MMCs is necessary before applying in the practical fields. This paper investigates the suitability of different non-traditional methods for machining MMCs by studying the machining mechanism, tool wear, surface finish, machining speed based on information available in the literature. This will link the all the understanding achieved by different researcher and, scientifically and systematically analyses those to give a details picture of machining MMC by non-traditional processes.

\section{Electrical discharge machining}

Electrical discharge machining (EDM) is the one of the most extensively used non-conventional material removal processes where electrical discharge is used to machine electrically conductive parts regardless of hardness (Ho and Newman 2003). The electric discharge generates high thermal energy which removes material by erosion (Abrate 1992). EDM process takes place in a dielectric fluid where the tool is one electrode in the shape of the cavity to be produced and the workpiece to be machined is the other electrode. The tool is then feed toward the workpiece in a controlled path to produce the shape of electrode or its movement. The electrode and the workpiece do not make direct contact during EDM process. Therefore, this process eliminates issues related to chatter and vibration. Electro-discharge machining (EDM) is a multipurpose process for machining intricate or complex which has typical advantage in the manufacture of mould, die, automotive, aerospace and

surgical components from materials which are difficult to machine by conventional methods. It is possible to drill a hole as small as $0.1 \mathrm{~mm}$ by EDM (Ho and Newman 2003).

\subsection{EDM mechanism of MMC}

During EDM the tool is connected to the negative terminal of a pulsating DC power supply and workpiece is connected to the positive terminal of the same source (Muller and Monaghan 2000) where pulsating direct current supply occurs at the rate of approximately $20,000-30,000 \mathrm{~Hz}$ ( $\mathrm{Ho}$ and Newman 2003). The tool is gradually brought close to the workpiece. When the distance between tool and workpiece reaches to a certain value the electricity starts to flow through the electrolyte from tool to workpiece and generates sparks. At this stage the thermal energy generates a channel of plasma between the tool and workpiece where the temperature can be as high as $20,000^{\circ} \mathrm{C}$ (Ho and Newman 2003). This temperature is high enough to melt and vaporise workpiece material, and make tiny crater. It also causes tool wear. Thus the distance between tool and workpiece increases and the 
tool moves further to maintain certain amount of gap facilitate electric spark. This process of melting and evaporating material from the workpiece surface is very dissimilar to that of conventional machining processes where chips are produced. When the plasma channel breaks down and turns off, the temperature reduces suddenly which allows dielectric fluid to circulate and implore the plasma channel, and flush the molten material from the pole surfaces in the form of microscopic debris. A typical material removal rate by this method is in the range of $10^{-6}-10^{-4} \mathrm{~mm}^{3}$ per discharge (Ho and Newman 2003). EDM process can be divided into two types, such as die-sinking and wire. The shape of the die is machined into workpiece by feeding the die into workpiece in the die-sinking EDM. On the other hand, in wire electro-discharge machining (WEDM) a thin wire is used as the tool electrode (Abrate 1992; De Garmo 2011). The size of the cut is always bigger than the size of the tool or wire in EDM. This is known as overcut which is constrained by the minimum distance (between electrodes necessary for spark. As the material removal in this process takes place through melting and vaporization, a recast layer of workpiece material on the surface and a heat affected zone below the surface of the workpiece are generated (De Garmo 2011).

Generally, the EDM characteristics of MMCs are similar to those occurring in a monolithic material. However, the presence of reinforcement particles makes the process slower and introduces additional complexity. This is because of the decrease in thermal and electrical conductivity of MMCs caused by the nonconductive and high melting point reinforcements. Material removal rate is generally higher at the beginning of machining but slows down due to the entrapment of reinforcement particles into the spark gap (Hocheng, Lei et al. 1997). While the wire performing EDM of particle reinforced metal matrix composites it encounters the ceramic particles and the EDM process becomes different to that of monolithic metals. There might be three kinds of situations, such as (i) the particle completely inside the slit width (PCSW), (ii) the particle partly in solid material and partly inside the projection of wire diameter (PPWD) (iii) the particle partly in solid material and partly in melted material (PPMM). Figure 1(a) shows a typical wire EDM process of particle reinforced MMC. It is seen from the literature that the wire diameter is around ten times bigger than that of reinforced particle diameter. Thus the diameter of the wire is much bigger compare to that of particles in the figure. This is a graphical presentation and it is not to the scale. Figure 1(b) shows the different situations which arise due to relative location of particles with respect to the wire.

The width of the slit is always bigger than the diameters of the wire as the clearance requirements of EDM process and melting of the workpiece takes place around the wire during EDM. The particles which are completely inside the slit width (PCSW) are initially exposed from the matrix material as the materials in front and sides of the particles start to melt and disappear. At this stage the non- 
conductive particles may have contact with the wire. In addition the materials at the back of reinforced particles are protected from melting for a while. The protrudes of the reinforced particles may create some scratches on the wire which are responsible for wire failure (Yan, Tsai et al. 2005). In addition, the exposure of entire $\mathrm{SiC}$ particles during EDM when machining the PRMMC results in a tendency for arcing to occur. This arises under inadequate flushing conditions during which the removed ceramic particles trap sufficient molten aluminium droplets to form a conductive path between the electrodes, and this leads to abnormal arcing (Muller and Monaghan 2000). In the same time the interruption in melting of the matrix material delays the EDM process. After certain stage the material at the back of particle melts which dislodges the particles and these are then washed away by electrolyte. It is reported that the reinforced particles don't melt during EDM process (Gatto and Iuliano 1997). Many particles were observed in the electrolyte. Thus, their full size and sharp corners were visible in the machining debris and in the recast layer (Fig. 2). This appears to suggest that the removal of the composite material occurs through the process of melting and vaporising the matrix material around the ceramic particle and at some point the entire SiC-particle becomes detached (Muller and Monaghan 2000).

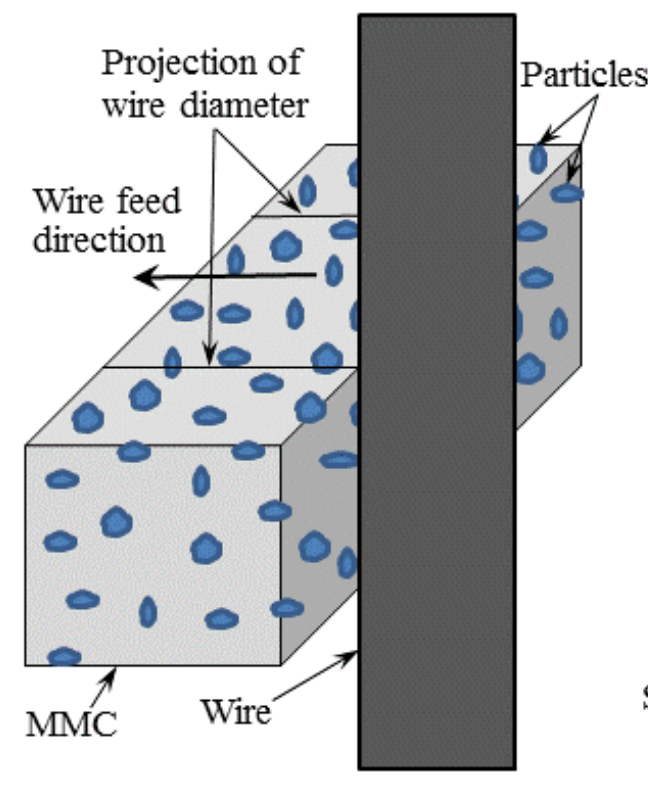

(a)

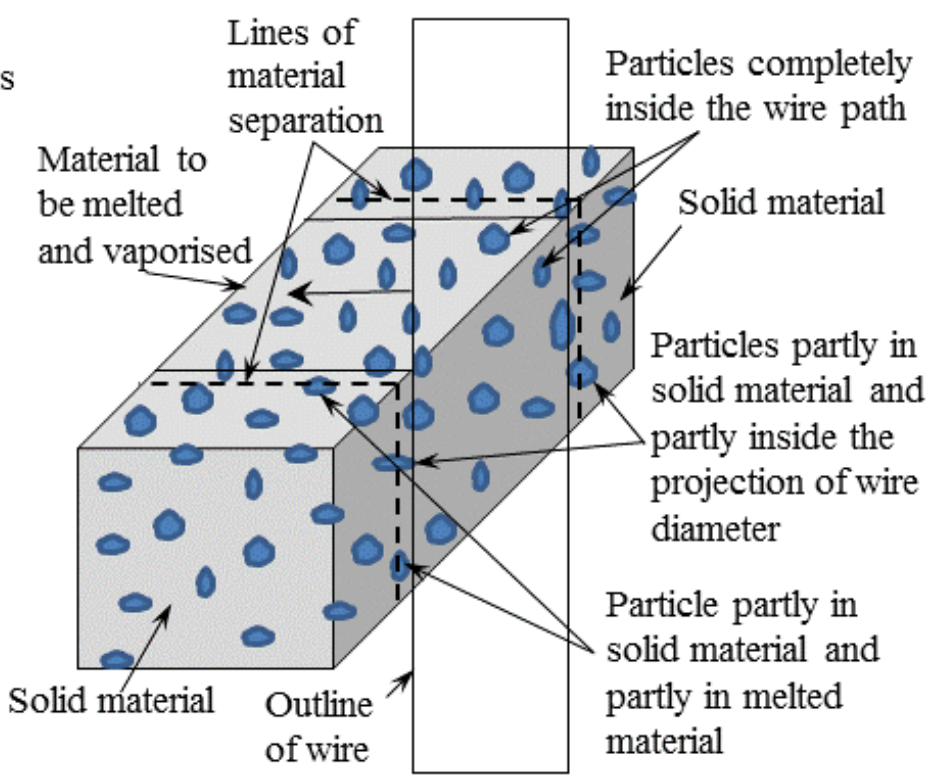

(b)

Fig. 1 Typical wire EDM process of particle reinforced metal matrix composite

Some particles which are partly in solid material and partly inside the projection of wire diameter (PPWD) encounter different situations during EDM. In this case the reinforced particles are hold by the solid matrix material. The exposed parts of the particles stay on the way of wire. This distracts the course of wire as well as promotes the wire breaking (Fig. 3). Finally, either wire breaks or particle breaks/dislodges and the process continues. The wire shifted (Fig. 3) due to impedance by 
protruding of reinforcement particles as well debris in the slit which causes bandings on the machined surface under low wire tension only (Yue, Dai et al. 1996; Yan, Tsai et al. 2005).

The particles partly in solid material and partly in melted material (PPMM) do not interact with the wire but exposed in the machined surface as material from front melts away due to EDM (Yan, Tsai et al. 2005). In these cases, $\mathrm{Si}$ diffuses to matrix material from $\mathrm{SiC}$ due to very high temperature. The presence of $\mathrm{Si}$ is noted in the recast layer by several researchers. During EDM an extremely high temperature is produced at those areas where the plasma channel strikes the electrodes. However, as a result of the high-pressure field around the discharge channel, the main removal process takes place after the interruption of the discharge. Subsequently, not all the material melted during the discharge phase is removed. The remaining molten material will resolidify by quenching at an extremely high rate due to the flushing by the dielectric, and hence a layer of re-cast material is formed. Fig. 2 shows that the rapid cooling results in a change in the microstructure of the matrix material. It is evident that the white spots found in the non-affected bulk material disappear within the re-cast layer. The reinforcement and the cupper precipitate in the thicker re-cast layer during rough machining condition. The thickness of the recast layer without reinforcement decreases under finishing machining conditions (Gatto and Iuliano 1997). In this case, voltage $120 \mathrm{~V}$, pulse current $32 \mathrm{~A}$, pulse-on duration $6.4 \mathrm{~ms}$ and frequency $22 \mathrm{kHz}$ were considered as the rough machining conditions. On the other hand, voltage $120 \mathrm{~V}$, pulse current 16-8 A, pulse-on duration 1.6-0.8 ms and frequency $125-200 \mathrm{kHz}$ were considered as the finish machining conditions. It is interesting to note that EDM of a non-reinforced aluminium alloy produces no significant re-cast layer (Muller and Monaghan 2000). This indicates that the reinforced particles are main contributor for formation of recast layer, the thickness of which is influenced by the machining conditions. In addition, the number of cracks on the MMC surfaces is much lower compare to that of monolithic metals after EDM (Gatto and Iuliano 1997).

Muller et al., (Muller and Monaghan 2000) analysed the silicon, aluminium, copper, magnesium, iron and nickel content by EDS-XR - analysis. The content maps indicated that the white spots shown in the electron microscope image contain higher percentages of copper, iron and nickel, compared to the other areas within the matrix. Since these white spots disappear in the matrix material within the re-cast layer it can be assumed that the iron, nickel and copper diffuse into the aluminium, resulting in a homogenised alloy structure due to melting and fast re-solidification of the material. The resolidified machined surface, usually known as the recast layer, generally contains a micro-cracks and random voids which may be due to (1) debonding of reinforcements from soft matrix material, (2) imperfect joining of the molten droplets and (3) trapped gas during solidification. 
Surface damage is considered to be limited to the thickness of the recast layer (Hung, Yang et al. 1994). Reinforcement particles are least present on the recast layer, as most of the particles may get rake up and remove during machining (Gatto and Iuliano 1997). Only the particles that are partly embedded in the solid material and partly in the melted materials are existed in the recast layer. At higher voltage and current, it is more pronounced and hence the reinforced particles may deposit below the recast layer (Singh, Raghukandan et al. 2004).

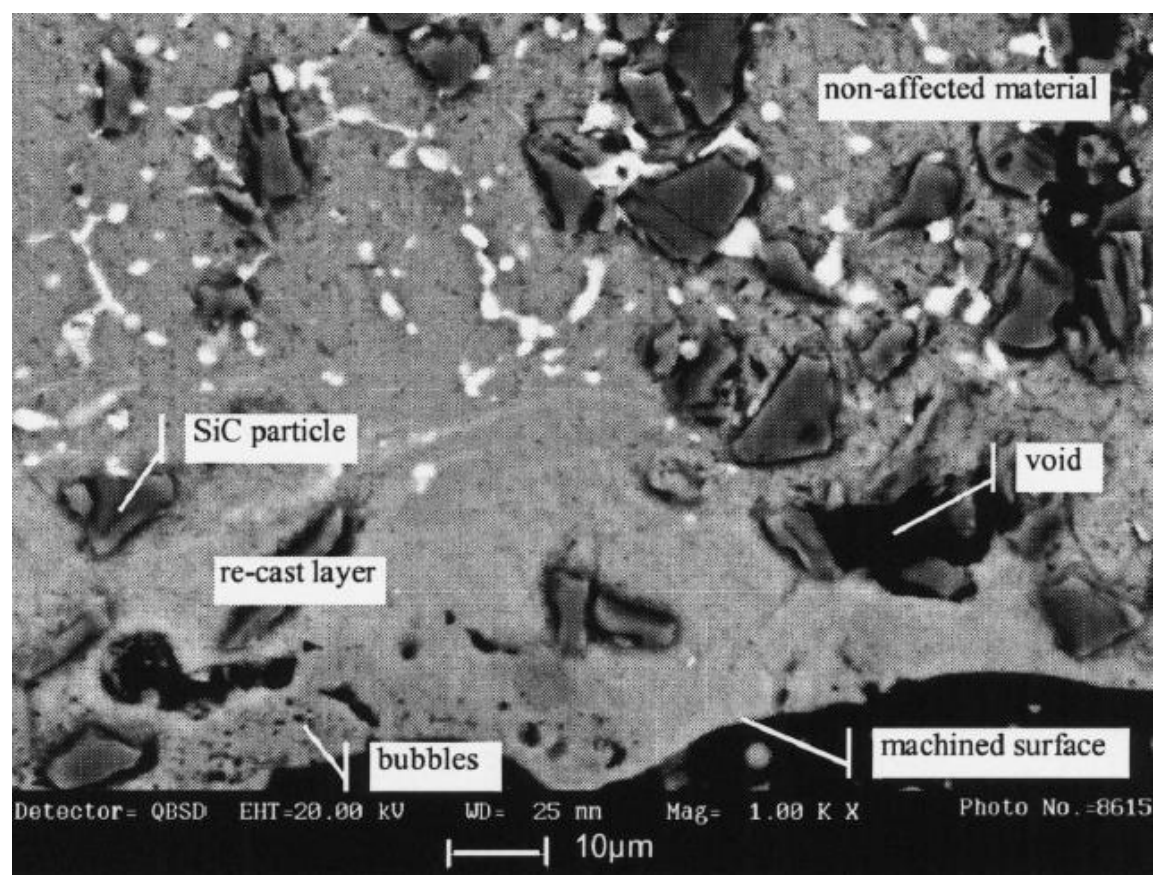

Fig. 2 Microstructure of recast layer (Muller and Monaghan 2000)
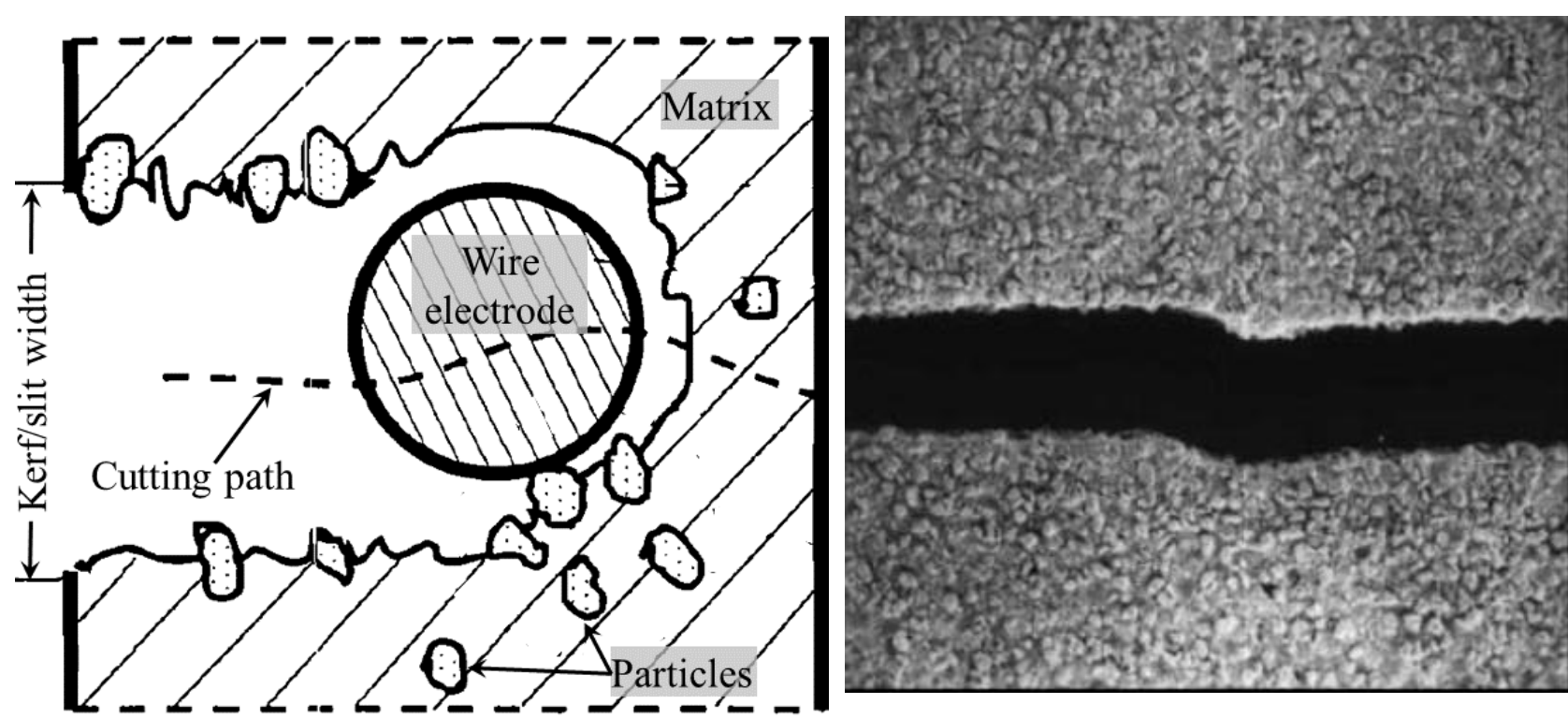

Fig. 3 Shifting of wire due to presence of reinforced particles in MMC during WEDM (Yue, Dai et al. 1996; Yan, Tsai et al. 2005) 
Generally, feed rate, material removal rate, surface roughness and tool wear increase with the increase of current, voltage and pulse on-time during EDM process (Rozenek, Kozak et al. 2001; Mohan, Rajadurai et al. 2002; Ramulu, Rao et al. 2002; Singh, Raghukandan et al. 2004).

\subsection{Cutting speed during EDM of MMC}

The feed/cutting speed during WEDM of MMCs significantly depends on the type and amount of reinforcement (Rozenek, Kozak et al. 2001). Fig. 4 presents the effect of current on cutting speed during $\mathrm{EDM}$ of $20 \% \mathrm{SiC}$ reinforced $\mathrm{AlSi} 7 \mathrm{Mg}$ at different pulse-on times and constant voltage $50 \mathrm{~V}$. In this case the tool was a negatively polarized brass wire of $0.25 \mathrm{~mm}$ diameter at speed of $10 \mathrm{~m} / \mathrm{min}$ and wire tension of $10 \mathrm{~N}$. The figure shows that the cutting speed increases with the increase of current. But the rate of the increase of the speed increases with the increase of pulse-on time. This is due to increase of the energy with the increase of current and pulse-on time.

Fig. 5 depicts the effect of voltage on the cutting speed for $20 \% \mathrm{SiC}$ and $\mathrm{Al}_{2} \mathrm{O}_{3}$ reinforced $\mathrm{AlSi} 7 \mathrm{Mg}$ metal matrix composites where current $3 \mathrm{~A}$, pulse-on time $1.6 \mu \mathrm{s}$ and pulse-off time $8 \mu \mathrm{s}$. It shows that the cutting speed decrease initially with the increase of voltage but with the further increase of the voltage the cutting speed increases for both of the MMCs. However, the rate of increase and decrease of speed is not similar. In case of $\mathrm{SiC}$ reinforced $\mathrm{MMC}$, the cutting speed is much higher than that of $\mathrm{Al}_{2} \mathrm{O}_{3}$ reinforced MMC.

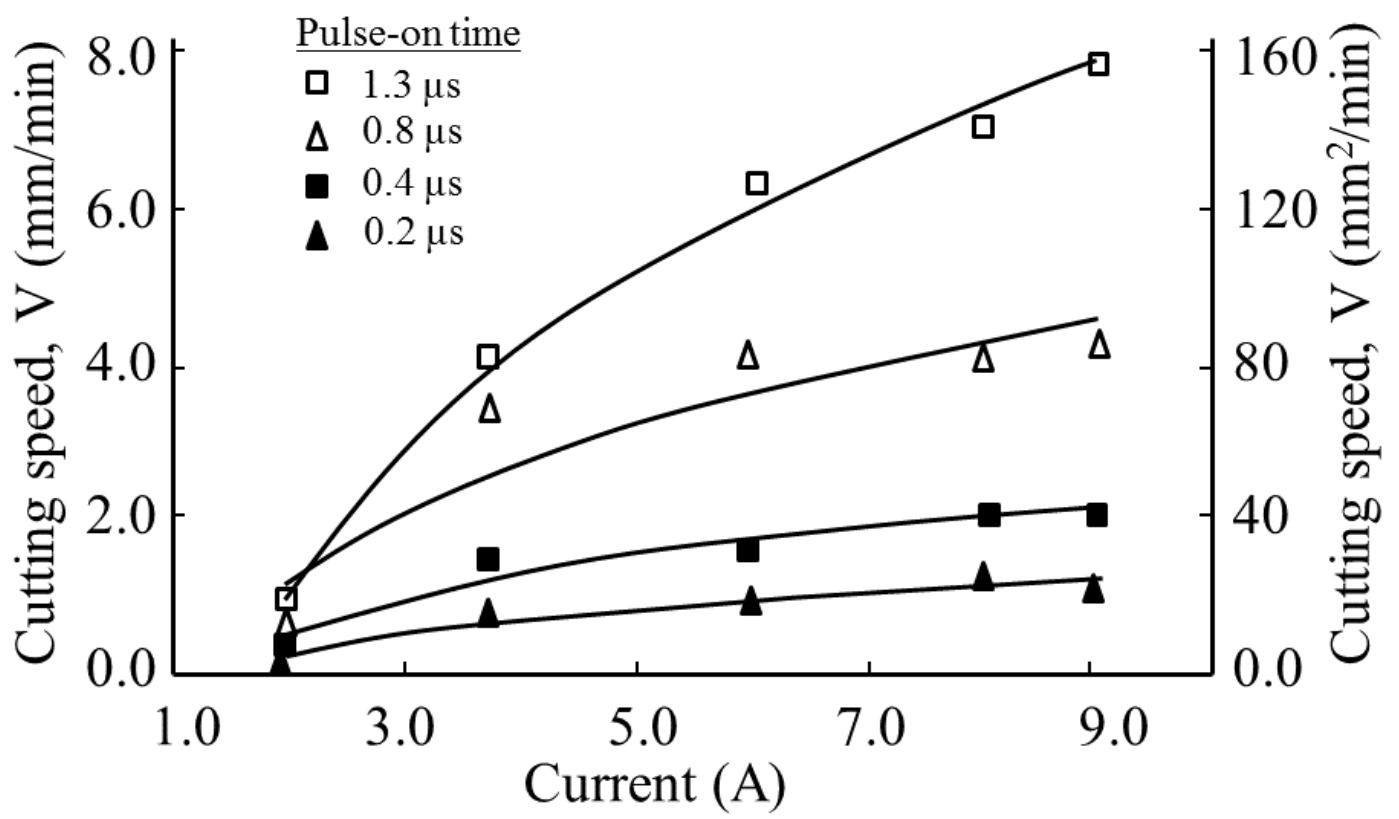

Fig. 4 Effect of current on cutting speed for $\mathrm{AlSi} 7 \mathrm{Mg} / 20 \% \mathrm{SiC}$ composite at different pulse-on times reinforcement (Rozenek, Kozak et al. 2001). 


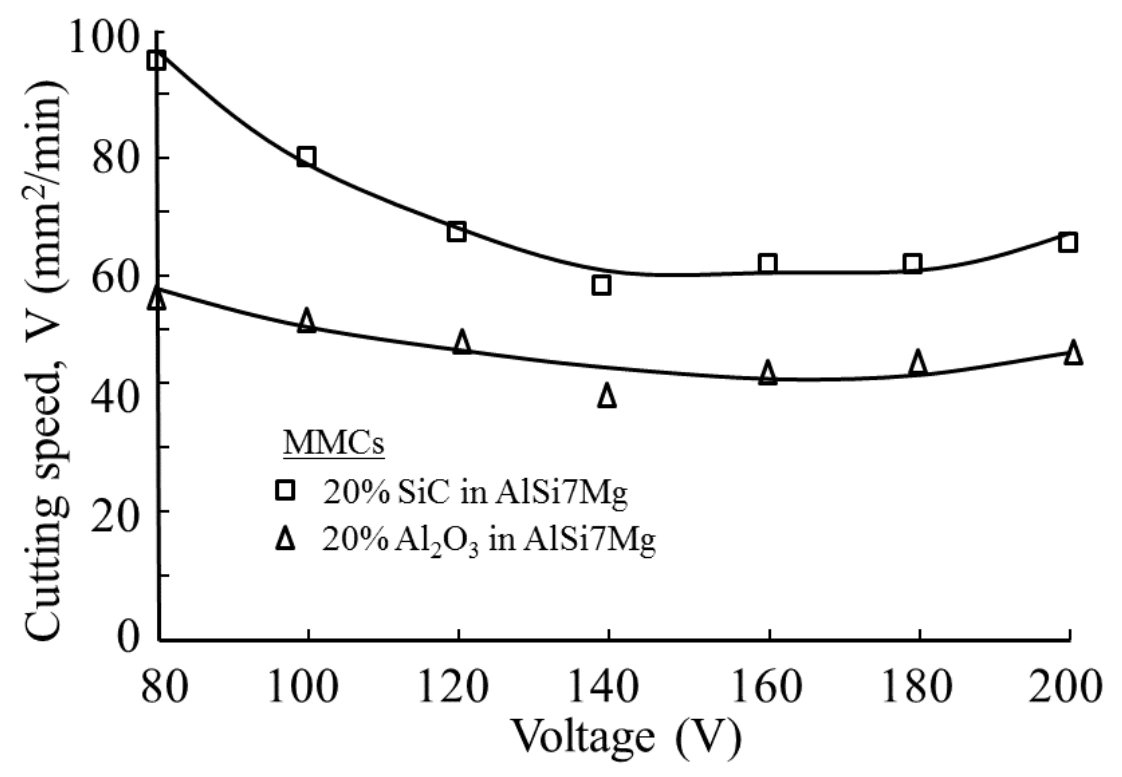

Fig. 5 Effect of voltage on cutting speed for different MMCs (Rozenek, Kozak et al. 2001).

It is already mentioned that the presence of reinforcement particles reduces the cutting speed of MMCs compare to its matrix materials. The machining time for materials with $25 \%$ fibre reinforcement is almost double that for those with 15\% fibres (Ramulu, Rao et al. 2002). This effect has been clearly depicted in Fig. 6 where the effect of pulse-on time on cutting speed has been presented for different volume percentages of MMCs. However, a considerable reduction of cutting speed for MMCs is noticed at higher pulse-on time. A similar cutting speed is noted at short pulse-on time for all the materials considered in the figure. With the increase of pulse-on time the difference among the cutting speeds of different materials emerged. But the cutting speeds of both 10 and 20 vol. \% $\mathrm{Al}_{2} \mathrm{O}_{3}$ composites did not show a substantial difference. Increased volume fraction of reinforcement leads the wire to break with pulse-on time as low as $3.1 \mu$ s (Yan, Tsai et al. 2005). But no wire breakage was noted when the cutting speed was as high as $126 \mathrm{~mm}^{2} / \mathrm{min}$ for machining of $6061 \mathrm{Al}$ alloys.

The cutting speed of MMC also depends on other factors, such as wire speed, flushing rate and wire tension. Fig. 7 shows the effect of wire speed on the cutting speed for MMCs with different reinforcement contents. It is clear from the picture that the cutting speed increases with the increase of wire speed though the rate of increase of cutting speed is higher at lower wire speed compare to that of higher wire speed. The wire electrode has to sustain discharge energy for longer time in the machining zone at lower wire speed. Thus the performance of the wire is very low at low speed. In case of MMCs with $20 \% \mathrm{Al}_{2} \mathrm{O}_{3}$ the wire is unable to cut as it breaks due to high temperature. As the wire speed increases the time to sustain discharge energy decreases and machining zone becomes 
cleaner which give higher tool performance and higher cutting speed. Fig. 8 presents the effect of flashing rate on the cutting speed for the MMCs with different reinforcement contents. It shows that the increase of flashing rate increases the cutting speed almost linearly for both the MMCs considered here. The flashing process mainly renews the electrolyte in the spark gap and removes the debris from the machining. The increase of flashing rate accelerates the renewing as well as debris removal processes which increase the cutting speed of MMCs. At a low velocity of dielectric fluid, short-circuiting becomes less pronounced due to accumulation of particles into the spark gap. This improves the material removal rate. On the other hand, a higher velocity/flushing pressure prevent the formation of ionized bridges into the spark gap. This causes a higher ignition delay and decreased discharge energy, thus reduces material removal rate (Singh, Raghukandan et al. 2004). In case of electro-discharge drilling (using hollow tool), material removal rate increases with the increase of flushing pressure (Yan and Wang 1999; Wang and Yan 2000). Although eccentric through-hole in a rotational electrode during drilling blind hole gives higher material removal rate but the tool wear rate is higher (Wang and Yan 2000).

The effect of wire tension on the cutting speed is shown in Fig. 9. The cutting speed decreases with the increase of wire tension. It is interesting to note that the difference between speeds of the two MMCs decrease with the increase of wire tension. The increased tension reduces the capacity of the wire to sustain the discharge energy and initiates the tendency to break. Thus smaller speed is achieved at higher wire tension.

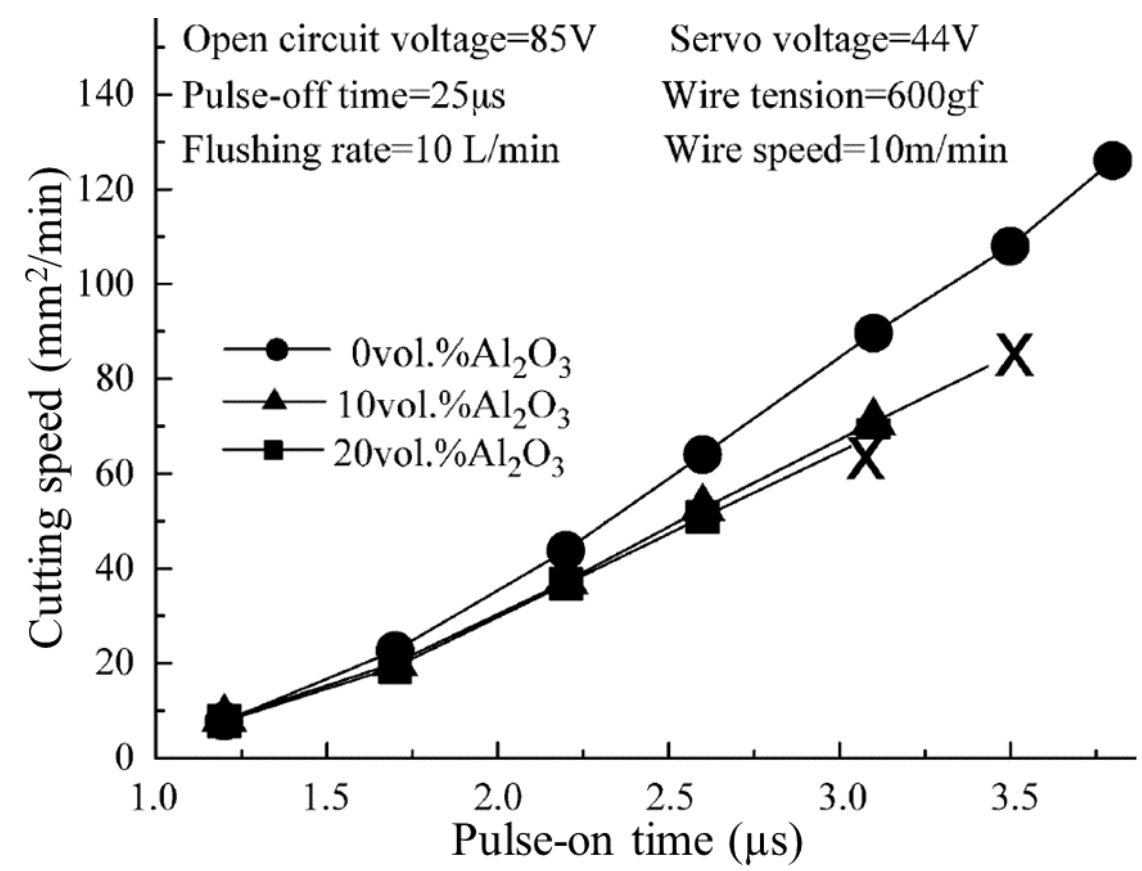

Fig. 6 Effect of pulse-on time on cutting speed of MMCs for different reinforcement content(Yan, Tsai et al. 2005). 


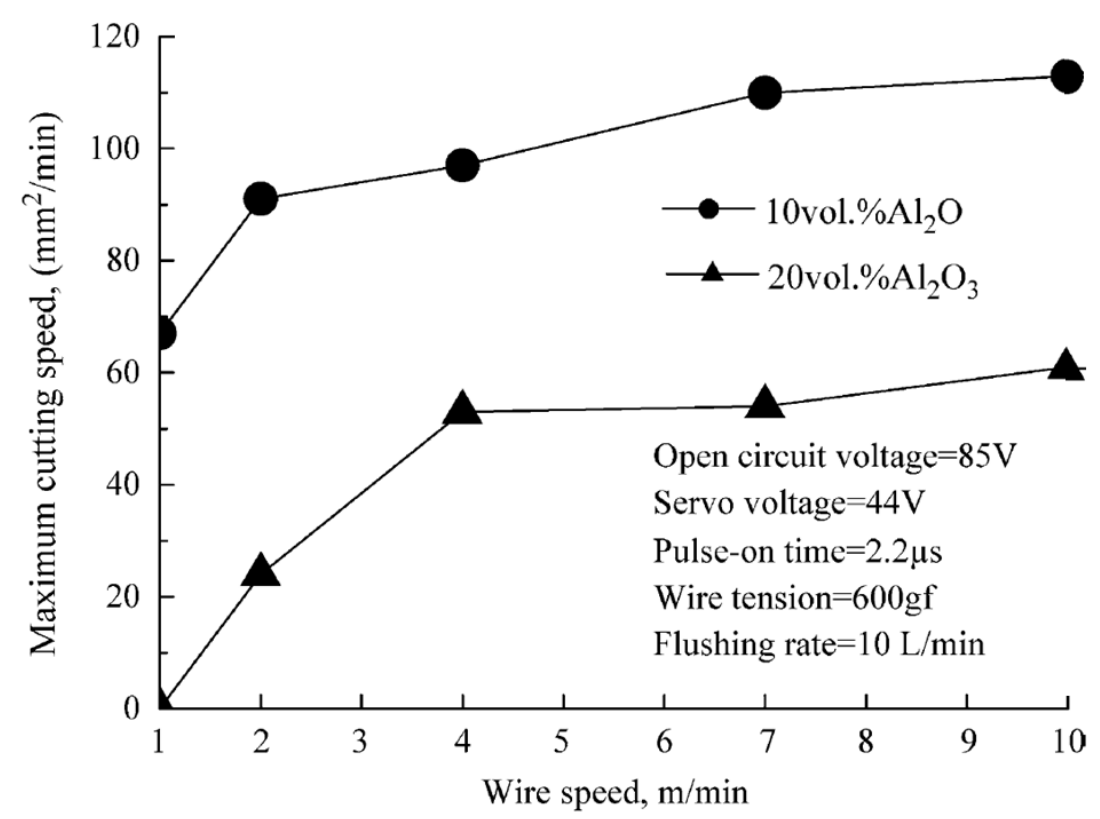

Fig. 7 Effect of wire speed on cutting speed for different reinforcement percentages (Yan, Tsai et al. 2005).

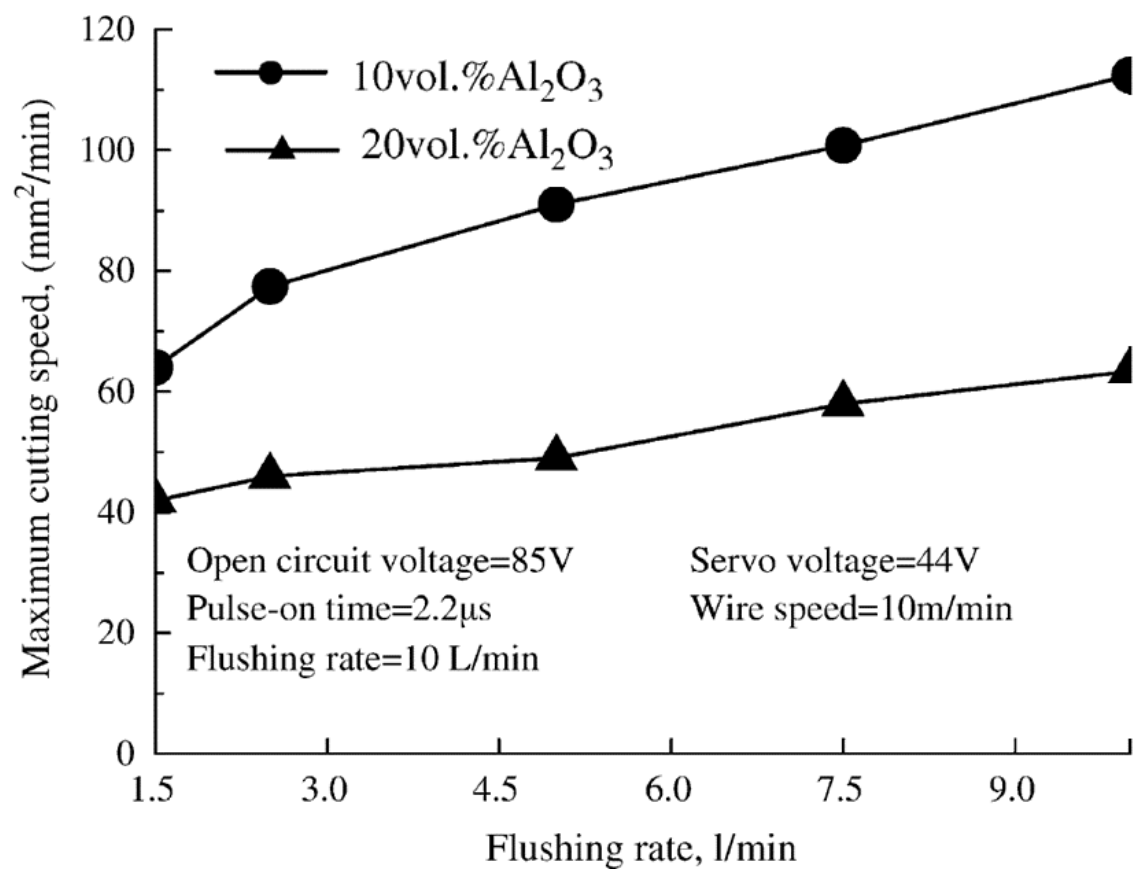

Fig. 8 Effect of flushing rate on cutting speed for different reinforcement percentages (Yan, Tsai et al. 2005).

\subsection{Tool wear and breakage}

Electrode with higher melting temperature has better wear resistance during EDM. For example, the wear rate of brass is greater than copper due to the higher melting temperature of copper (Ramulu 
and Taya 1989). Tool wear rate on the negatively connected electrode is less than the positively connected electrode irrespective of the electrode material and the volume percentage of reinforcements. A rotary electrode increases material removal rate, decreases electrode wear and improves surface finish compared to a stationary electrode (Mohan, Rajadurai et al. 2002; Mohan, Rajadurai et al. 2004). While performing WEDM on 6061Al alloys, 10 vol.\% Al2O3p/6061 Al composite and $20 \mathrm{vol} . \% \mathrm{Al}_{2} \mathrm{O}_{3} \mathrm{p} / 6061 \mathrm{Al}$ composite Yan et al., (Yan, Tsai et al. 2005) noted that the wire tends to break near the middle of the machined surface for all the materials, when a lower discharge energy (current $20 \mathrm{~A}$, pulse-on time $3.5 \mu \mathrm{s}$ ) was applied. But this location of wire break changed when the discharge energy (current $22 \mathrm{~A}$, pulse-on time $3.8 \mu \mathrm{s}$ ) increased. In this case wires break below the middle, at the middle and above the middle of 6061Alalloy and,10 vol.\% $\mathrm{Al}_{2} \mathrm{O}_{3} \mathrm{p} / 6061 \mathrm{Al}$ and 20 vol.\% $\mathrm{Al}_{2} \mathrm{O}_{3} \mathrm{p} / 6061 \mathrm{Al}$ composite machined surfaces. Yan et al., (Yan, Tsai et al. 2005) suggested that for 6061 Al alloy wires break below the middle of the machined surface because the increase in the discharge energy enlarged the width of slit, stabilizing the cutting process, such that the wire electrode wears uniformly. On the other hand, for the composites the higher discharge becomes extremely large suddenly without increasing the discharge gap between the wire electrode and the workpiece in a dielectric. Thus, excess of melt is produced on the wire electrode which breaks the wire electrode in the upper edge of the machined surface.

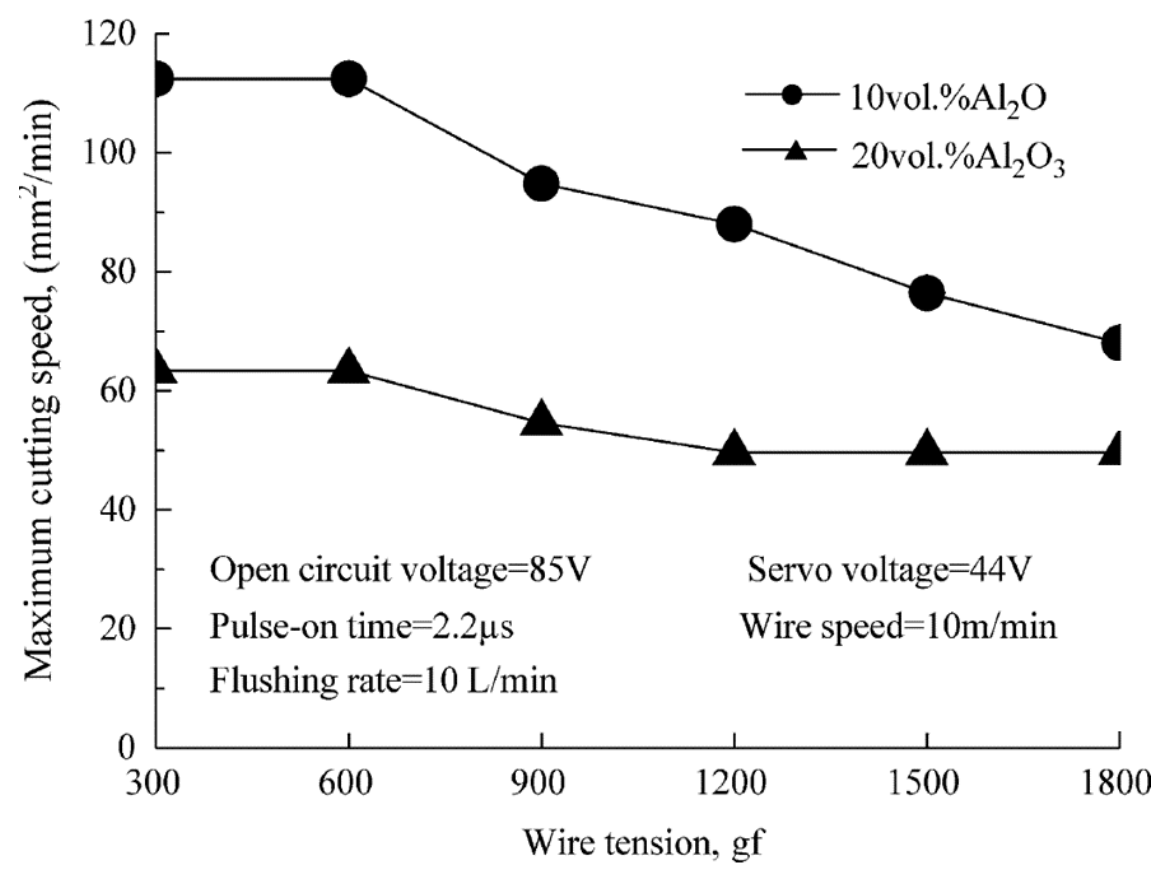

Fig. 9 Effect of wire tension on cutting speed for different reinforcement percentages (Yan, Tsai et al. 2005).

Generally, the breaking of wire occurs at critical discharge energy during the WEDM processes. The critical discharge energy may be achieved by adjusting machining parameters, such as by increasing 
pulse-on time values (Yan, Tsai et al. 2005). Fig. 10 shows that wear rate of wire electrode tool increases with the increase of the volume percentage of reinforcements and pulse-on time. Yan et al.,(Yan, Tsai et al. 2005) attributed this to the relative increase of discharge energy with the increase of the pulse-on time. In addition, (i) formation of abnormal arc discharge (Liao, Chu et al. 1997)and (ii)the interactions of the solid particles with the wire increases with the increase of volume percentage of reinforcement which contribute to higher wear rate to the tool electrode. The SEM pictures of wires in Fig. 11 also support the increase of tool wear with the increased volume percentage of reinforcements. The figure shows that the craters on the wire surface became deeper and wider as the percentage $\mathrm{Al}_{2} \mathrm{O}_{3}$ particles in MMC increased.

The wire also breaks occurs because it is softened by the high temperature during machining which reduces the tensile strength of the wire material. Thus, if the wire is placed at high tension during EDM it may break easily. The flushing of machining zone by the electrolyte reduces the temperature and removes debris. Thus, increase of flashing rate enhances the tool life and cutting speed. The reduced wire speed allows the wire to stand higher discharge energy per unit time which accelerates the wire breaking(Yan, Tsai et al. 2005).

Tool wear reduces at higher velocity/flushing pressure because of higher cooling rate of the tool (Singh, Raghukandan et al. 2004). (Singh, Raghukandan et al. 2004). The tool wear rate increases with the increase of flushing pressure in case of electro-discharge drilling (using hollow tool) (Yan and Wang 1999; Wang and Yan 2000). For effective EDM of MMCs, large current and short on-time has been recommended (Hocheng, Lei et al. 1997).

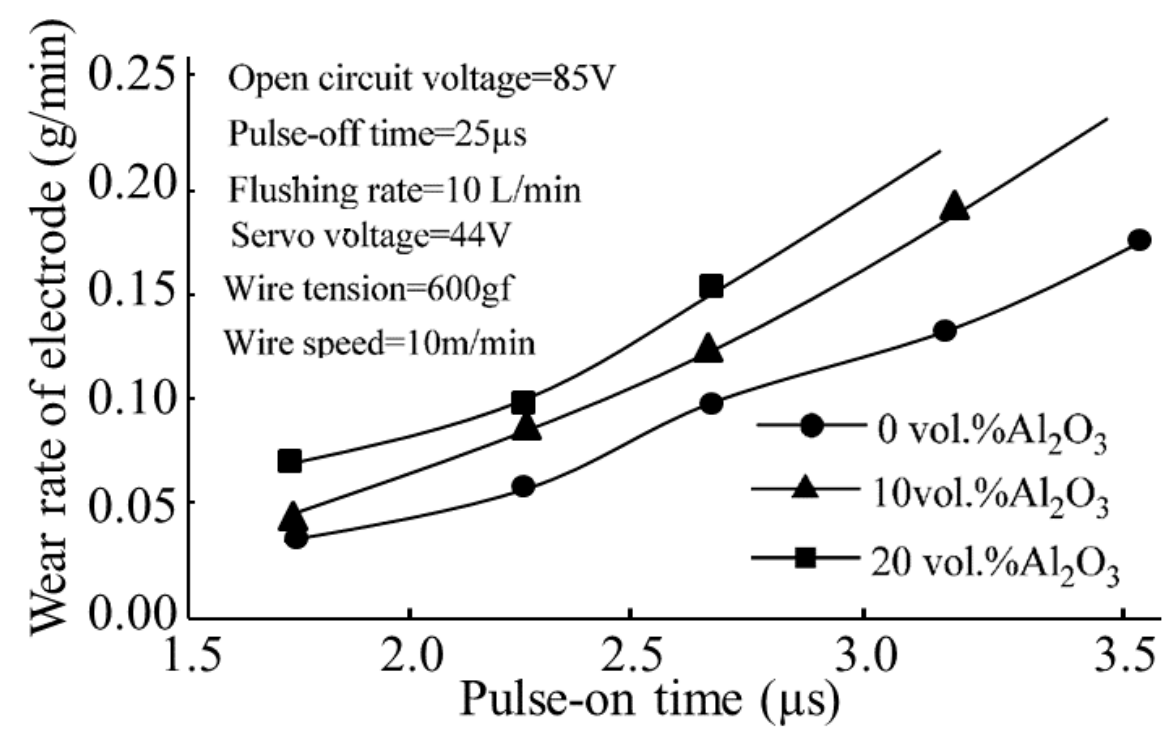

Fig. 10 Effect of pulse-on time and reinforcement percentage on the wear rate of electrode (Yan, Tsai et al. 2005) 

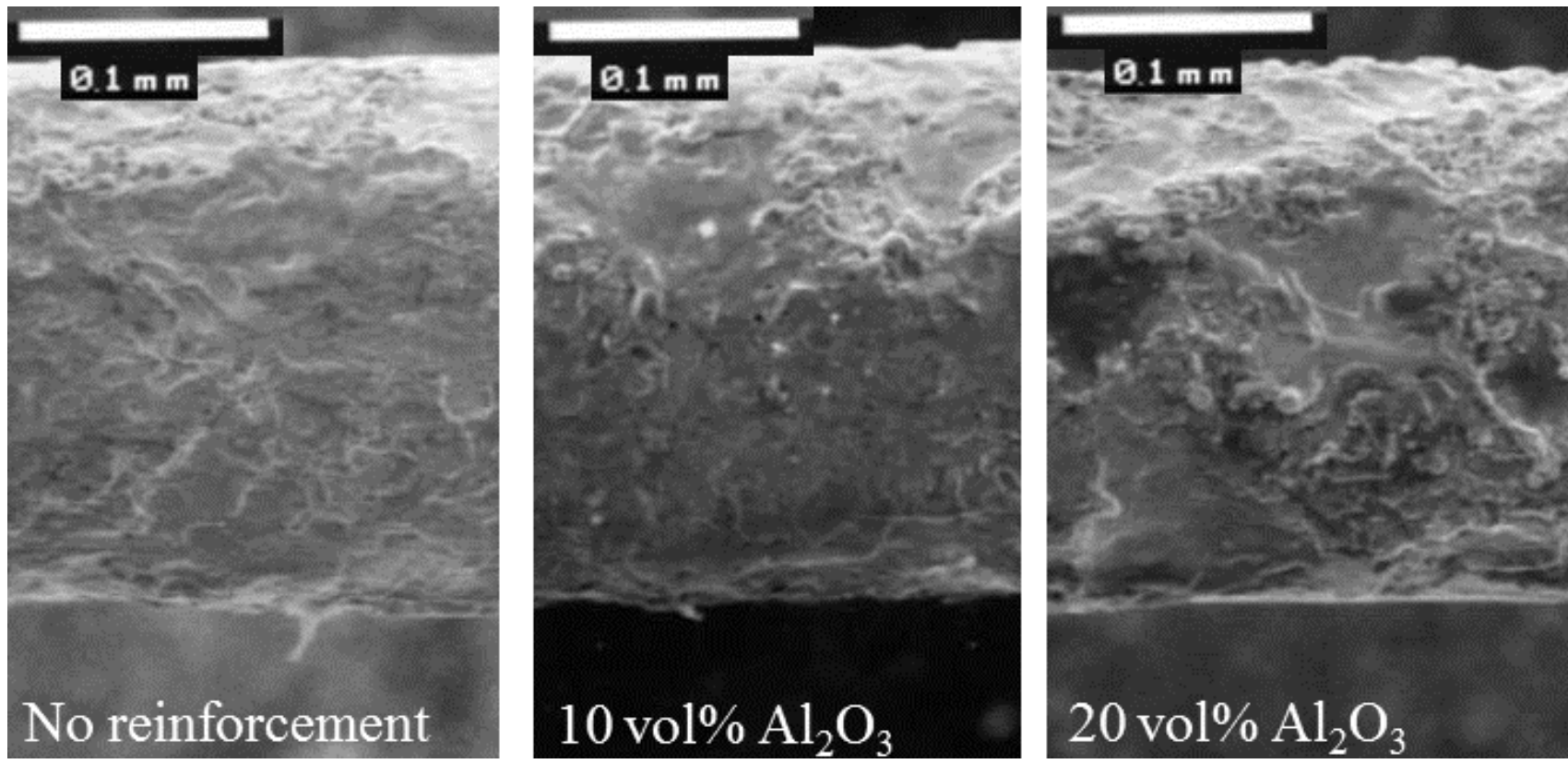

Fig. 11 Pictures of tool surface after machining matrix material and different MMCs (Yan, Tsai et al. 2005).

\subsection{Surface finish and dimensional accuracy}

The machined surface of a material generated using EDM is composed of many microscopic craters associated with the random spark discharge between the electrodes. Such an EDM topography is presented in Fig. 12, the crater structure with its high peaks adjacent to valleys of removed material is clearly evident. The size of the craters produced on the workpiece surface depends mainly upon the energy of the discharge which is a function of machining parameters (Muller and Monaghan 2000). Fig. 13 shows that the finest surface from EDM is achieved on 6061Al alloy matrix material $\left(0\right.$ vol. $\% \mathrm{Al}_{2} \mathrm{O}_{3}$ p). The $\mathrm{MMC}$ reinforced with 20 vol. $\% \mathrm{Al}_{2} \mathrm{O}_{3}$ exhibited the roughest surface. Slight increase of the surface roughness was noted with the increase of pulse-on time for matrix material and MMC with 10 vol. \%. The surface roughness of $\mathrm{MMC}$ with 20 vol. $\% \mathrm{Al}_{2} \mathrm{O}_{3}$ did not change notably with the increase of pulse-on time. At higher pulse-on time $\mathrm{MMC}$ with 10 vol. $\% \mathrm{Al}_{2} \mathrm{O}_{3} \mathrm{p}$ shows the finest surface finish at pulse-on time of $3.1 \mu \mathrm{s}$. It seems that this MMC has the properties for which high discharge energy as well as enlargement of discharge craters may be prevented. The discharge energy is defined as the product of peak current, no-load voltage and pulse-on time (Yan, Tsai et al. 2005). Fig.12 (a) shows that the surface of matrix material contains irregular features of solidified melted materials features. The density of this feature increases and the feature becomes less pronounced (Fig. 12 (b)) on the machined surface of $\mathrm{MMC}$ reinforced with 10 vol. $\% \mathrm{Al}_{2} \mathrm{O}_{3}$ particles though particles are not visible which might be coated with the matrix material. The 
presence of reinforced particles protects the matrix material from melting at higher depth from the machined surface. In addition, these particles reduce the fluidity of the molten matrix material (Muller and Monaghan 2000). Thus, changes in the feature of the machined surface. For the same reasons the machined MMC surface is mainly dominated by reinforced particles (Fig. 12(c)) with further increase of volume percentage reinforced particle $(20 \%)$. The density of the feature on the machined surface further increased in this case.

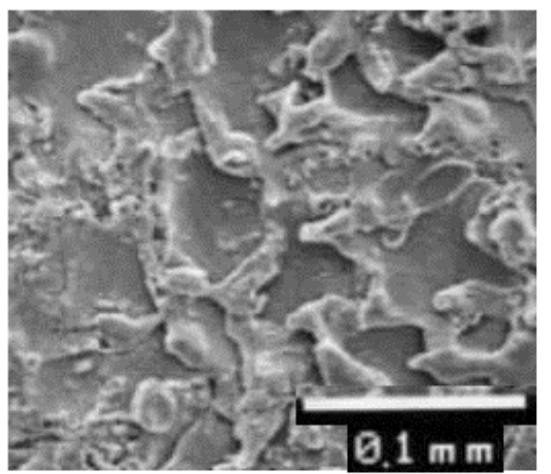

(a) Matrix material

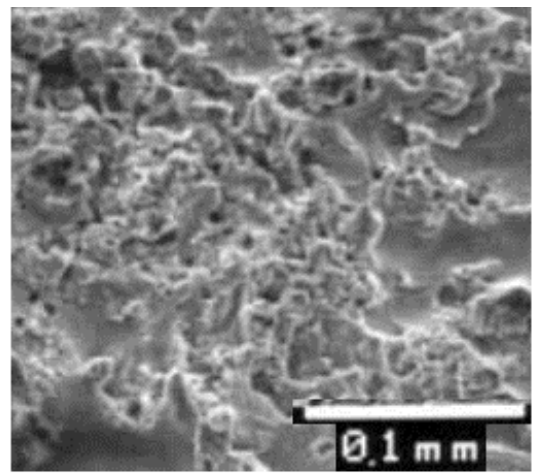

(b) 10 vol\% reinforcement

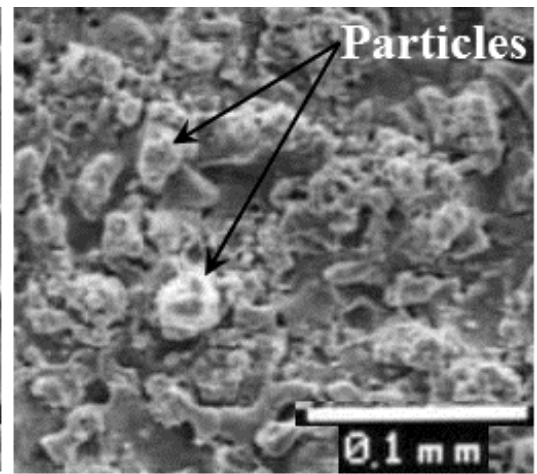

(c) 20 vol\% reinforcement

Fig. 12 Surfaces machine by EDM at pulse-on time $2.6 \mu$ s (Yan, Tsai et al. 2005)

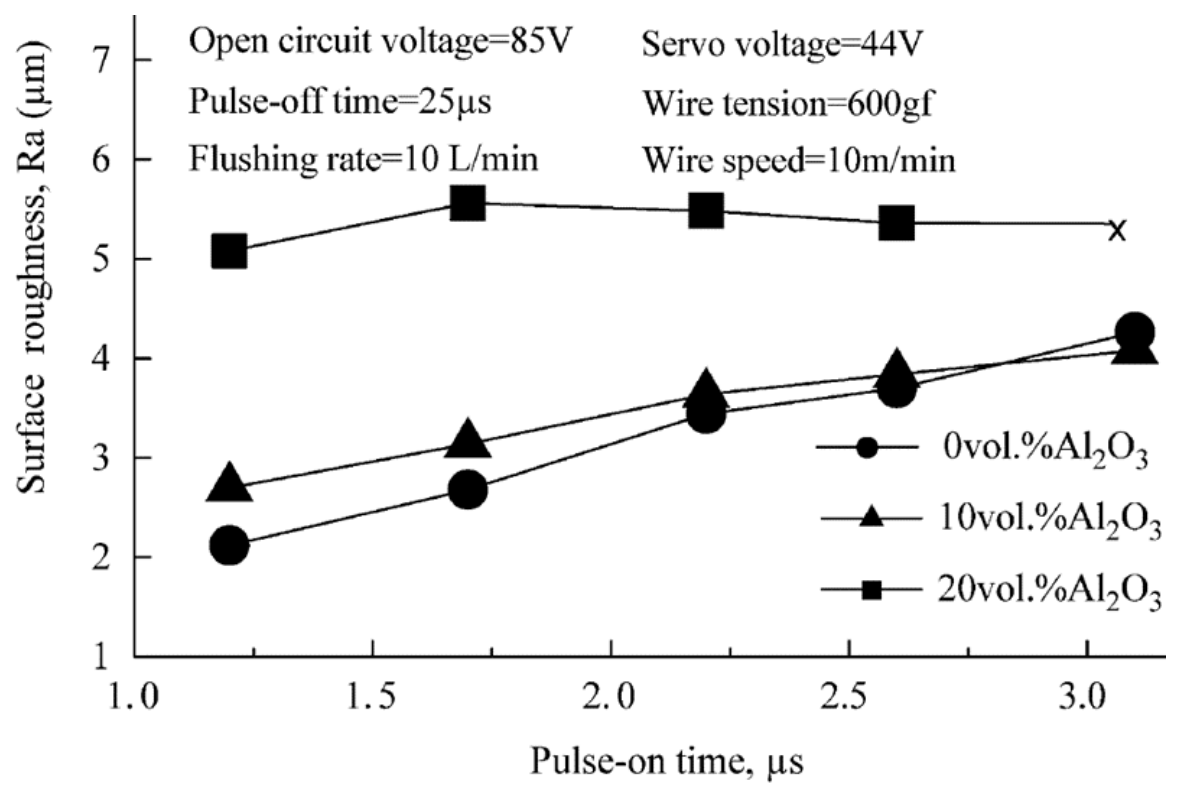

Fig. 13 Effect of pulse-on time on the surface roughness of matrix material and different MMCs (Yan, Tsai et al. 2005).

Fig. 14 shows that the surface roughness (Ra) varies between $1.5 \mu \mathrm{m}$ and $3.5 \mu \mathrm{m}$. It is evident that with the increase of current the surface roughness increases. Higher current results in a higher thermal loading on both the cathode and anode, followed by a higher amount of material being ejected. This results in a larger crater size and thus the surface finish becomes rougher. Furthermore, 
it is evident that machining with longer pulse duration also brings about an increase in surface roughness. Longer pulse duration results in a larger removal per discharge. The crater size therefore increases and consequently the surface roughness value increases (Rozenek, Kozak et al. 2001) . (Rozenek, Kozak et al. 2001) found that the effect of voltage is insignificant on the surface finish for the range considered (Fig. 15) These results do not follow the findings of Hung et al., (Hung, Yang et al. 1994) who maintained that the current alone dominates the surface finish.

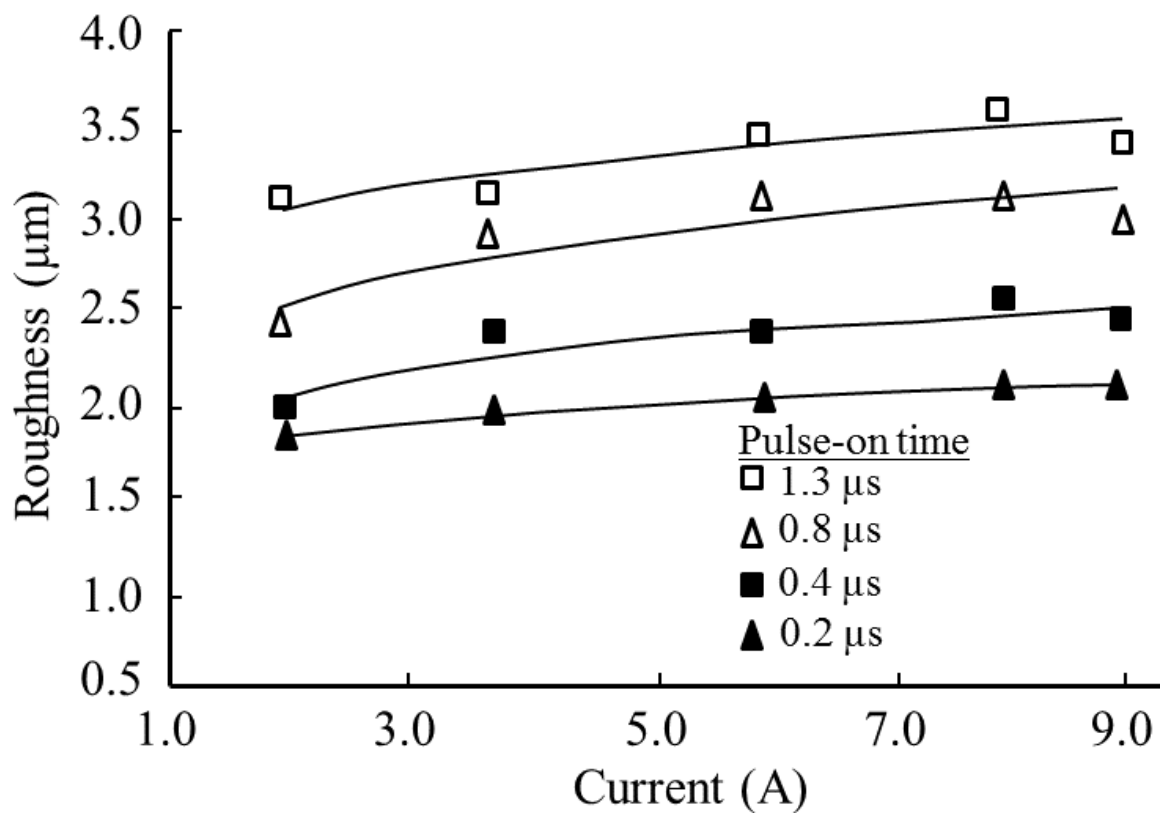

Fig. 14 Effect of discharge current on the surface roughness of AlSi7Mg reinforced with $20 \% \mathrm{SiC}$ where voltage $80 \mathrm{~V}$ and pulse-of time $14 \mu$ s (Rozenek, Kozak et al. 2001).

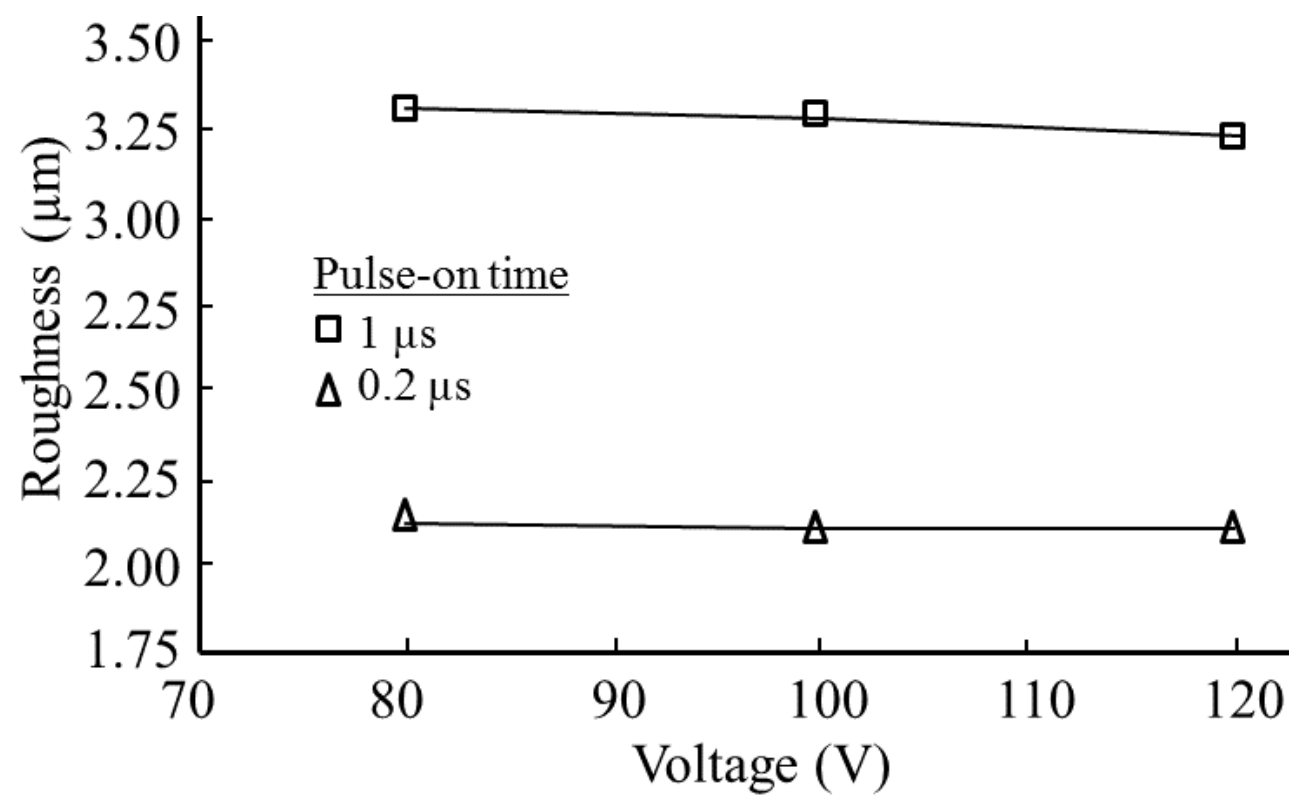

Fig. 15 Effect of voltage on the surface roughness of $\mathrm{AlSi} 7 \mathrm{Mg}$ reinforced with $20 \% \mathrm{Al}_{2} \mathrm{O}_{3}$ where discharge current 3 A and pulse-of time $1.6 \mu$ s (Rozenek, Kozak et al. 2001). 


\section{Laser-beam machining}

Similar to EDM, laser beam machining (LBM) is also one of the most widely used thermal energy based non-contact type advance machining process. However, the application LBM is not only limited to conductive materials but can be applied for almost whole range of materials. Electrolyte, electrodes, high voltage, electric spark, etc. do not exist in this case. But laser beam is focussed for melting and vaporizing the unwanted material from the parent material (Dubey and Yadava 2008). It is suitable for producing geometrically complex profile and making miniature holes in sheet metal. Laser-beam machining has the ability to produce as low as $0.25 \mathrm{~mm}$ width of the cut opening (kerf width) (Muller and Monaghan 2000). The effectiveness of the LBM process of any material depends mainly on thermal properties and partially on the optical properties rather than the mechanical properties of that material. Therefore, materials with favourable thermal properties, such as low thermal diffusivity and conductivity, regardless of brittleness or hardness, are particularly well suited for laser machining. The heat energy transfers from the laser to the material through irradiation in this process. Thus, cutting forces, mechanically induced material damage, tool wear and machine vibration are absent. The laser beam can be used for drilling, cutting, grooving, welding and heat treating processes on a single machine when attached with a multi-axis workpiece positioning system or robot (Pham, Dimov et al. 2007). $\mathrm{CO}_{2}$ and Nd:YAG lasers are most established among many types of lasers used for machining in industries(Dubey and Yadava 2008). Very few reports are found in the literature related to laser beam machining of metal matrix composites. Composites based on a high thermal conductive matrix are characterized by a low absorpwtion factor and are generally machined by a $\mathrm{CO}_{2}$ laser beam (Dahotre, McCay et al. 1989; Kagawa, Utsunomiya et al. 1989; Hong, Vilar et al. 1997).

\subsection{Machining mechanism}

The stages during LBM are: (i) melt, vaporize and chemical degrade, (ii) remove transformed material and (iii) cool down. Initially the high energy density laser bream is focussed on work surface and thermal energy transfers from the laser beam to the workpiece material. This thermal energy absorbed by the workpiece heats and transforms the work volume into a molten, vaporized or chemically changed state. Then a high pressure inert gas jet is used to prevent oxidation (Hong, Vilar et al. 1997) and remove the transformed material from the machining zone (Dubey and Yadava 2008). The melted materials that are not removed cool down, solidify and form the machined surface. Generally the diameter of a laser beam $(\approx 0.25 \mathrm{~mm})$ is much bigger than that of the reinforcements $(1-15 \mu \mathrm{m})$ in commonly used MMCs (Di Pietro and Yao 1995). A typical LBM 
process of MMC is given in Fig. 16. Unlike the EDM process, the reinforcement particles melts during LBM and substantial changes take place in the microstructure of MMC. In this case the laser beam focused on the top of the workpiece surface or little bit below the top surface (Hong, Vilar et al. 1997; Muller and Monaghan 2000). Thus the workpiece material starts to melt, vaporise and degrade from the top and continues towards bottom. The high pressure gas jet forces the transformed material towards the bottom and causes downward flow of the molten material during cutting. These cause striation pattern on the machined surface as well as dross attachment at the bottom of the machined surfaces as shown in the Fig 17. The formation of the striation is a complex issue which depends on the side way burning as well as machining conditions (Muller and Monaghan 2000).

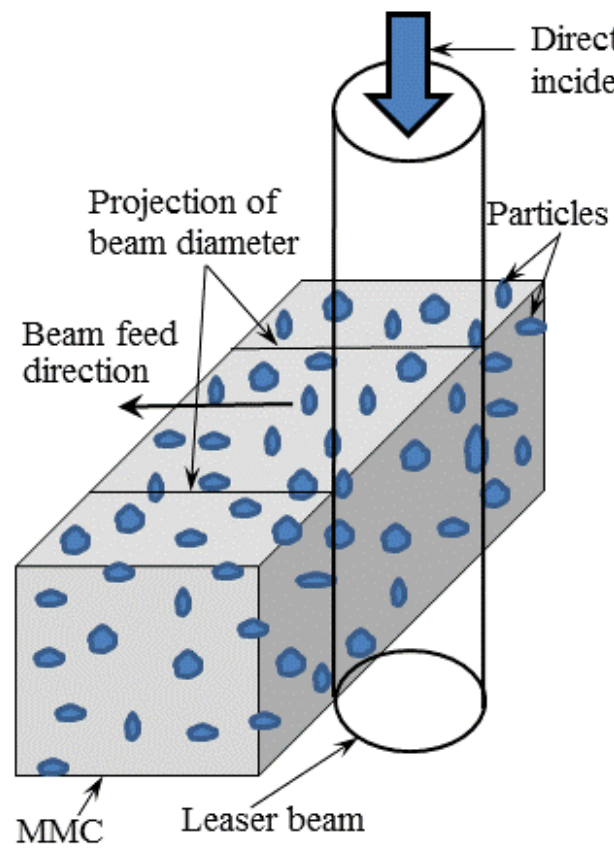

(a)

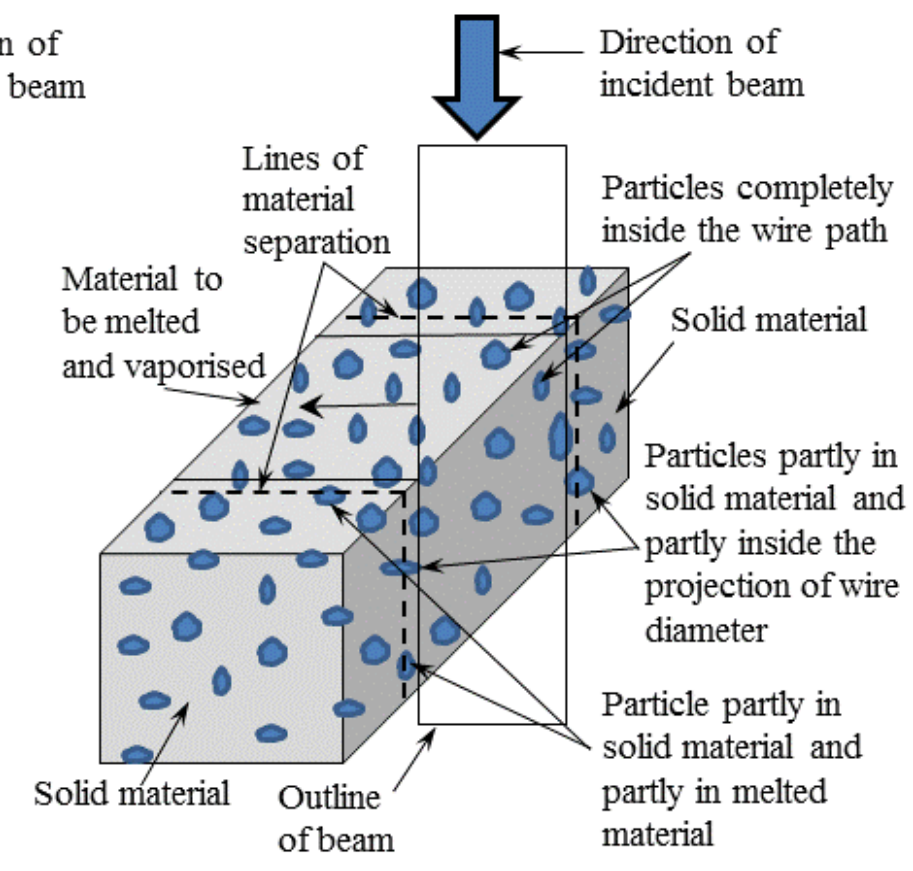

(b)

Fig. 16 A typical LBM process of particle reinforced MMC

In laser machining the damage is produced by excessive heating of the surface layer of the material and the microstructure of the matrix material is changed. The intense heat during laser machining melted the constituent materials and caused chemical reactions among those. Thus heat-affected subsurface layers are produced in the PRMMC. The chemical reaction between SiC and Al produces the plate/needle-like phases $\left(\mathrm{Al}_{4} \mathrm{C}_{3}, \mathrm{Al}_{4} \mathrm{SiC}_{4}\right)$ and free $\mathrm{Si}$. $\mathrm{Al}_{4} \mathrm{SiC}_{4}$ mainly appeared in the form of large platelets and its growth proceeded by solid state diffusion (Dahotre, McCay et al. 1989; Hong, Vilar et al. 1997). The extent of reaction between reinforcement and matrix can be controlled by the laser energy input (Dahotre, McCay et al. 1989). Three distinct regions (Fig. 18) are produced in the heat affected zone when laser cutting SiC reinforced MMCs (Yue and Lau 1996). Fig 18 shows white 
lines in the matrix material (Muller and Monaghan 2001) which is due to the deposition of copper and zinc at the aluminium grain boundaries. In this case, plate/needle-like phases with small SiC particles and blocky Si particles were found close to the cutting surface with a narrow width of 50$60 \mu \mathrm{m}$. Next to this region $(70 \mu \mathrm{m}$ in width) $\mathrm{SiC}$ particles were found to have redistributed with increased size and smoothed edges. Some large blocky Si, fine cellular/dendritic Al structures and $\mathrm{Al} / \mathrm{Si}$ eutectics are apparent in this region. This region was then followed by plate/needle-like phases $(8-10 \mu \mathrm{m}$ in size) nucleated at the surface of the $\mathrm{SiC}$ particles. Unmelted base materials were present next to this region (Muller and Monaghan 2000).

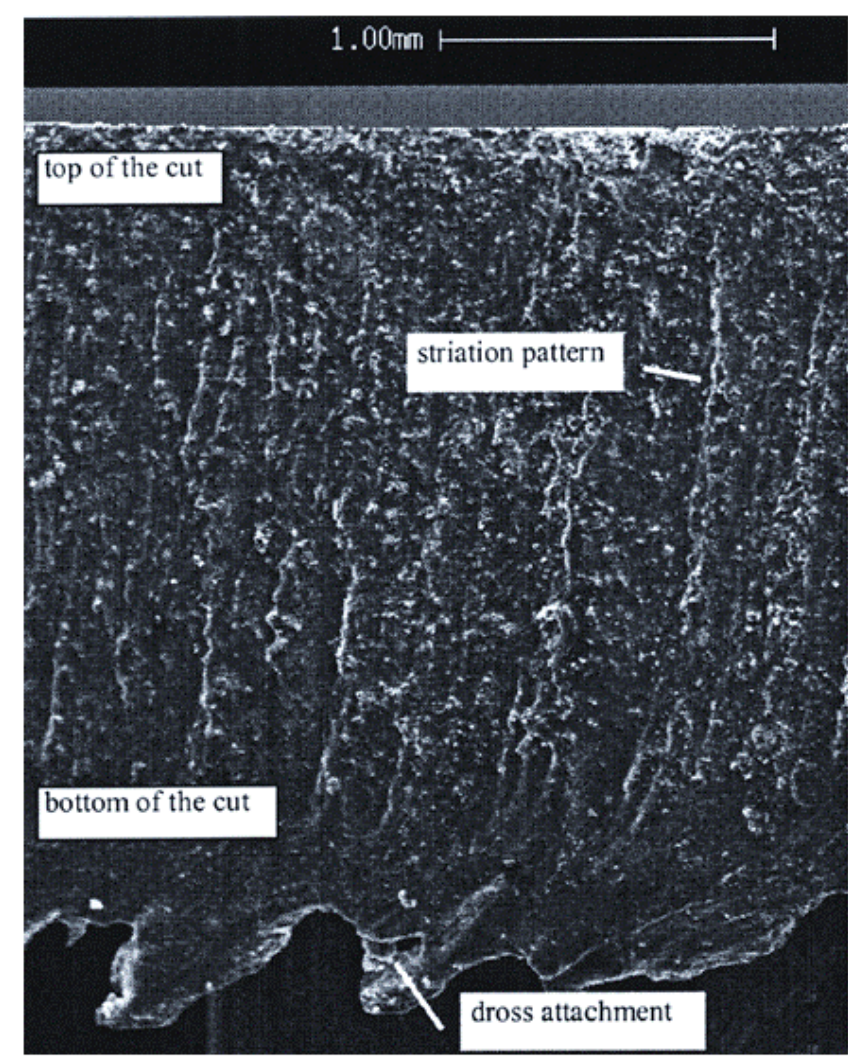

(a) $20 \mathrm{vol} \% \mathrm{SiC}$ in $\mathrm{AA} 2618$
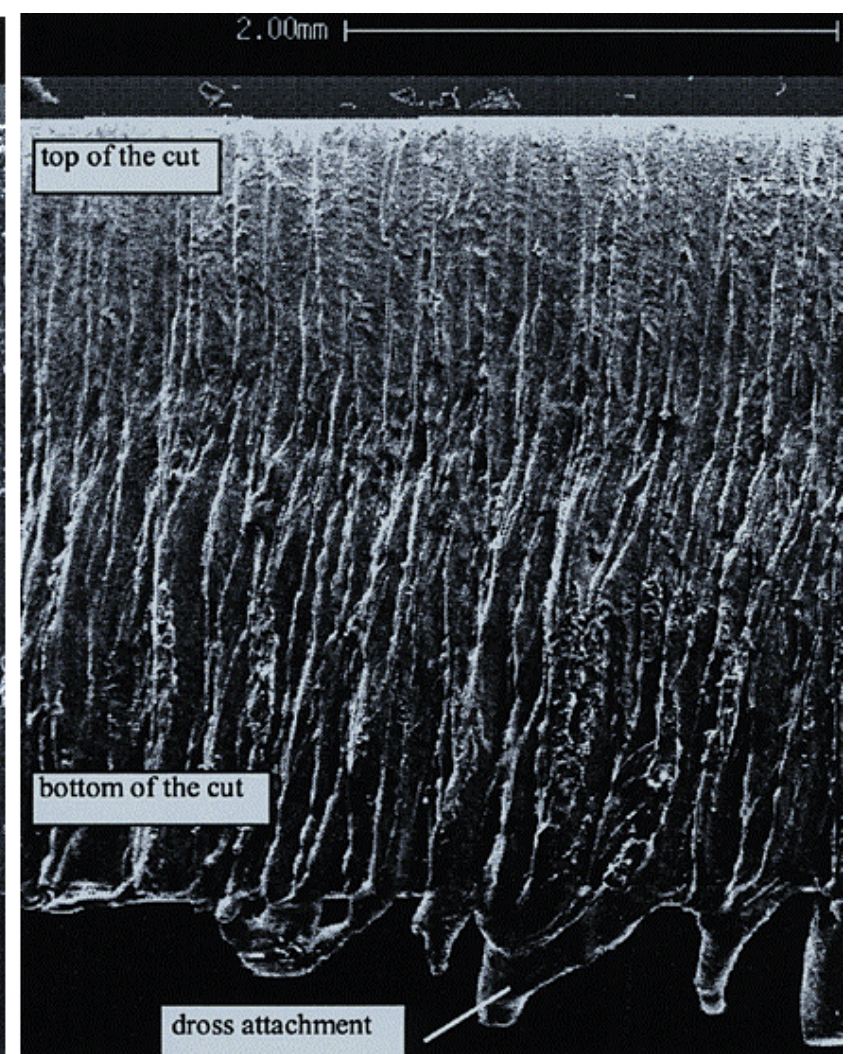

(b) Non reinforced AA2618

Fig. 17 Striation and dross attachment on the machined surfaces (Muller and Monaghan 2000)

The above phenomena happen when the melt can be blown out more easily during through cutting process. However, in case of less efficient removal of molten material, such as during laser-drilling of a blind hole, a wider heat affected layers are generated. Fig. 19 shows the microstructure and the concentration of the elements within the matrix material after laser drill of a blind hole. There are two sub-surface layers and the non-affected bulk material in this case as well but those are qualitatively different compare to that of through laser cutting processes. The three zones on the machined surface after laser drilling of blind hole in the AA2618/SiC/20p composite is described below (Muller and Monaghan 2001): 


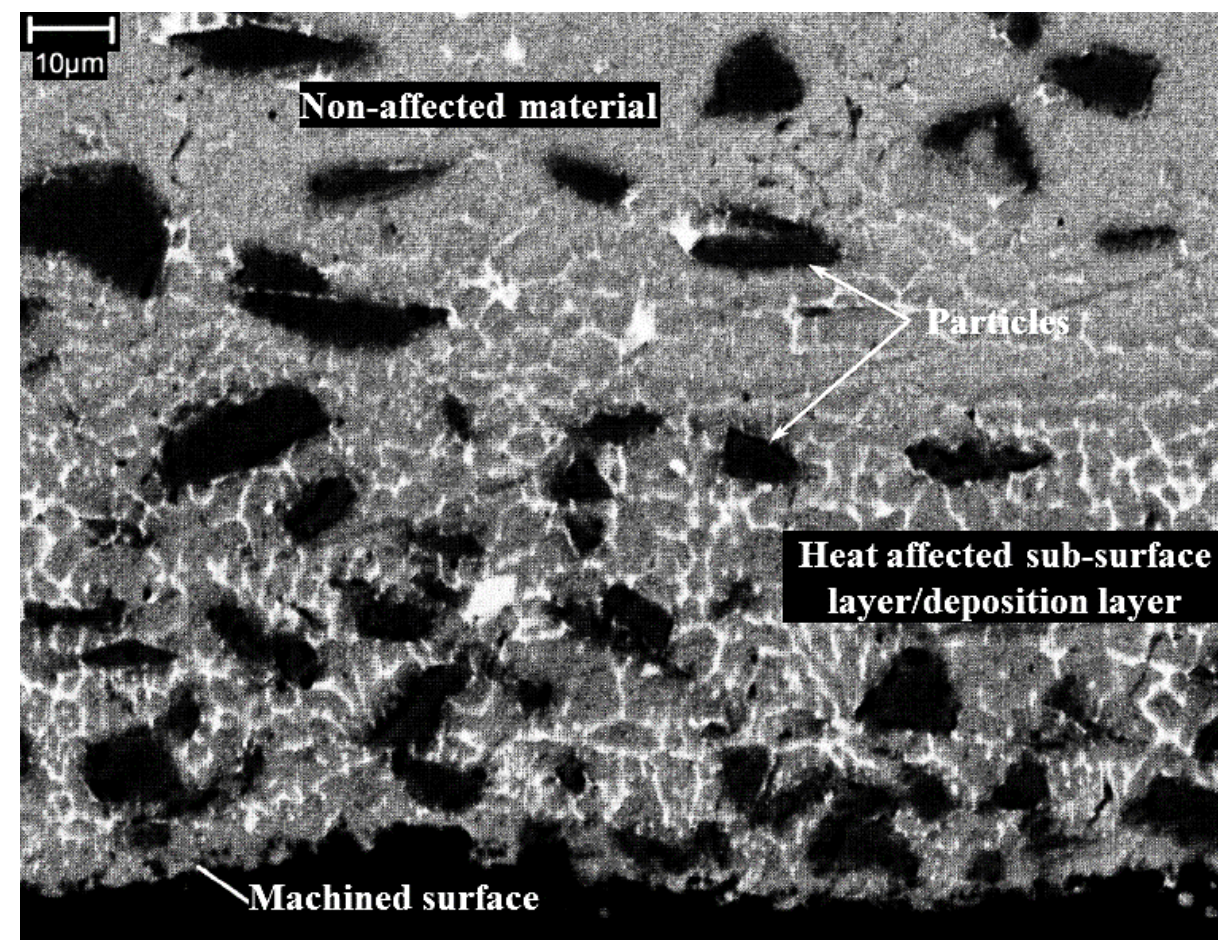

Fig. 18 Sub-surface layer of PRMMC after Laser cutting (workpiece mat: AA2618/SiC/20p; PRC $\mathrm{CO}_{2}$ Laser; $\left.P \mathrm{~L}=2 \mathrm{~kW} ; v=600 \mathrm{~mm} / \mathrm{min}\right)($ Muller and Monaghan 2000)

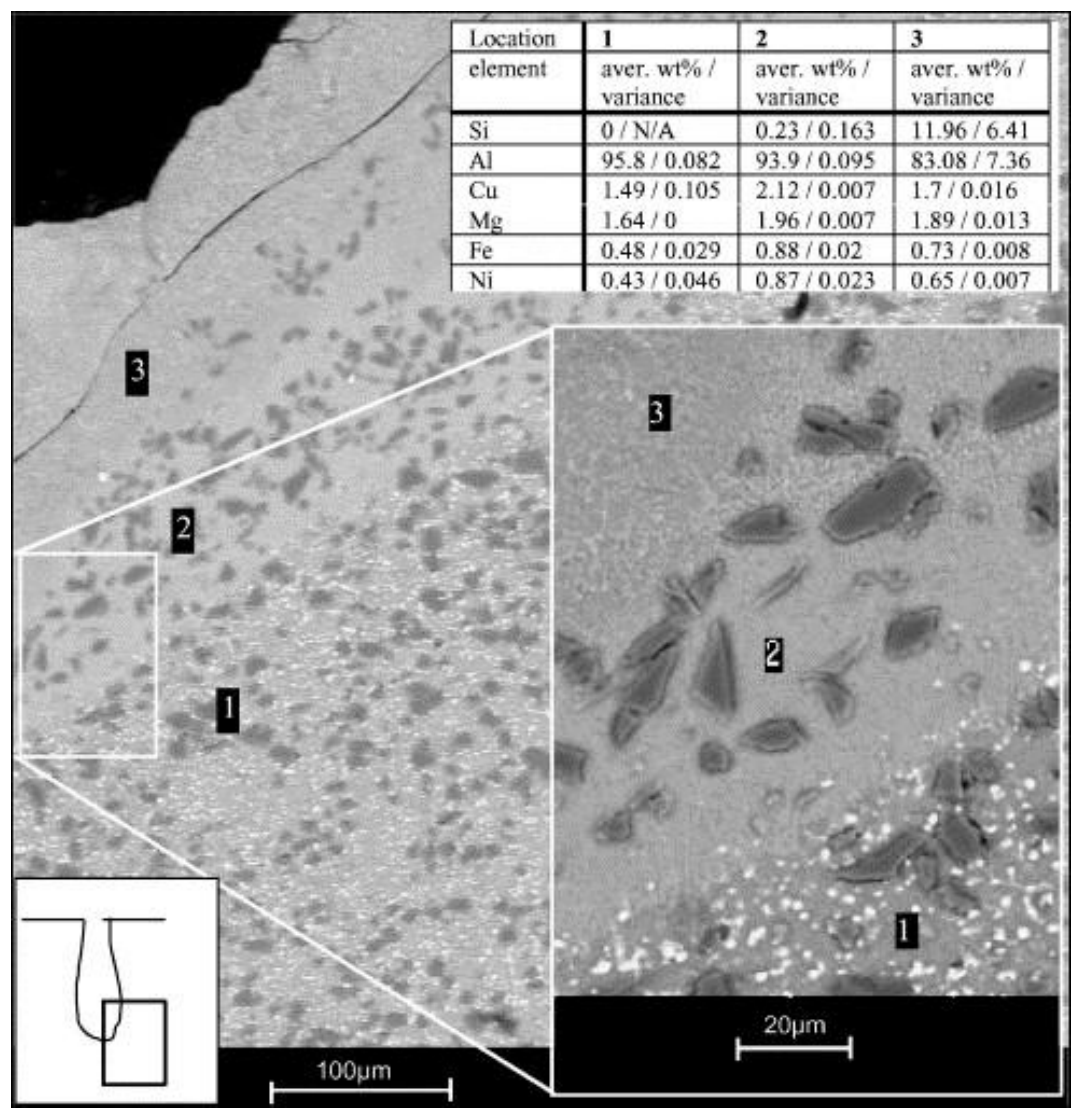

Fig. 19 Microstructure of the MMC after laser drill of a blind hole (Muller and Monaghan 2001) 
Zone (1): Unmelted base materials are present in this region.

Zone (2): The matrix materials melt and re-solidify in this region. This generates fine regular aluminium alloy where no silicon was noted. The $\mathrm{SiC}$ particles don't dissolve and are distinguishable from the matrix material. The white spot, which refers to high iron, nickel and copper content within the bulk material, disappear within this zone.

Zone (3): The SiC particle are melted and dissolve in the melted matrix material in this region. This is due to high temperature because of close and longer contact between leaser and metal matrix composite. The content of silicon increase to $12 \%$ in this zone compare to less than $0.5 \%$ in the other zones. The appearance of needle-like structure in this zone indicates the formation of $\mathrm{Al}_{4} \mathrm{C}_{3}$ (Hong, Vilar et al. 1997; Hu and Baker 1997). All these indicate that the laser machining induces a much higher thermal loading during less efficient removal of molten material.

\subsection{Cutting speed during LBM of MMC}

Cutting speed during LBM is an input parameter. However, the higher the cutting speed smaller the depth of cut. At a given power level of laser beam, higher speeds mean that a lower amount of energy is available to remove the material in the cut zone. Hence, the depth and width of the kerf decrease with an increase in the cutting speed. At a higher cutting speed the machined surface is very rough and straddled with striations due to the unsteady motion of the molten layer or intermittent plasma blockage. High volume SiC content 6061 Al MMC can be successfully laser cut to achieve a smooth cutting surface and a narrow heat affected zone at moderate cutting speeds with an argon shielding gas (Hong, Vilar et al. 1997).

\subsection{Surface finish}

Fig. 17 shows the topography of the surface machined by LBM. The intermittent flow of the molten material gives typical patterns on the machined surfaces (Di Pietro and Yao 1995). These patterns appear on the cut surface as relatively regular straight lines, which normally run at a slight angle dependent on the chosen cutting parameters (Muller and Monaghan 2001). The surface roughness increases with the increase of feed rate and cutting speed, and decrease of output power. The laser cutting tends to be intermittent at higher speed and feed. This results in a rougher surface (Lau, Yue et al. 1994). It was noted the thickness of this deposition layer decreases with increased feed rate. These results confirm that the dross height and the extent of the thermal damage are directly proportional to each other: minimising one results in minimising the other(Muller and Monaghan 2001). 
Fig. 17(b) shows the surface topography of the non-reinforced Al alloy matrix. The surface at the entrance of the laser is relatively smooth for non-reinforced Al alloy but around the middle the cut height the surface roughness is increased noticeably though this surface has a ductile appearance compare to that of MMC. It is suggested that the material at upper part of the surface is removed by vaporisation of the aluminium alloy which generates a smooth surface. However, in the lower part of the surface the material is melted by the laser and swept downwards by the high pressure gas jet. On the other hand the presence of $\mathrm{SiC}$ particles in PRMMC deters the vaporising process of the material during machining. In this case the material removal is mainly occurred by melt and blow. The smoother striation surface obtained on the PRMMC can be attributed to the more viscous melt, which hinders the striation formation (Muller and Monaghan 2000).

\section{Abrasive water jet machining}

The impact of solid particles is the basic event in the material removal by abrasive water jet machining where a jet of high pressure and velocity, water and abrasive slurry is used to cut the target material by means of erosion (Shanmugam, Chen et al. 2002). Though he abrasive water jet (AWJ) technology can be used for almost every material, it has received considerable attention in the machining of difficult-to-machine and thermal sensitive materials (Ramulu and Arola 1993; Kovacevic, Hashish et al. 1997). Machining with an AWJ can be applied for turning, milling and drilling (Hashish 1995). In comparison to thermal machining processes (laser, EDM), AWJ does not induce high temperatures and as a consequence there is no thermally affected zone (Muller and Monaghan 2000). The material removal in this process occurs generally by cutting the material rather than deformation wear (Muller and Monaghan 2000). It has omnidirectional cutting capability (Ramulu and Arola 1993) and can be considered to be a very fast machining process for MMCs as high feed rates are possible in this process (Hashish 1995). However, AWJ is very difficult to produce a workpiece with high geometrical accuracy.

\subsection{Machining mechanism of MMC by abrasive water jet}

It is already mentioned that small abrasive particles with water take part in removing material in AWJ machining. In this case the small abrasive particles act as cutting tools during machining. Most researchers used 80-mesh abrasive particles (Savrun and Taya 1988; Shanmugam, Chen et al. 2002) which are around $177 \mu \mathrm{m}$ in diameter (Kirk visited on 6th March 2014). The ceramic particles in the MMCs resist the deformation and wear of MMC. When the cutting tool for MMC has the size comparable to that of reinforcement particles then the machining mechanism becomes completely different to that of conventional machining. In that case, it is natural that the matrix material will be 
removed point by point more easily than that of reinforced particles as the reinforced particles are harder than the matrix material. However, the mechanism of material removal highly dependent on the size of abrasive particles relative to that of reinforced particles. The typical nozzle diameter of jet is more than $1 \mathrm{~mm}$ (Savrun and Taya 1988; Wang 1999) which is much bigger than that of reinforced particle. A typical abrasive water jet machining mechanism is illustrated in Fig. 20. It shows that the individual particle removes small amount of material by tiny cutting edges at a time. With the combined effect of many particles a significant amount of material is removed. However, some particles also embed in the matrix martial after machining (Savrun and Taya 1988).

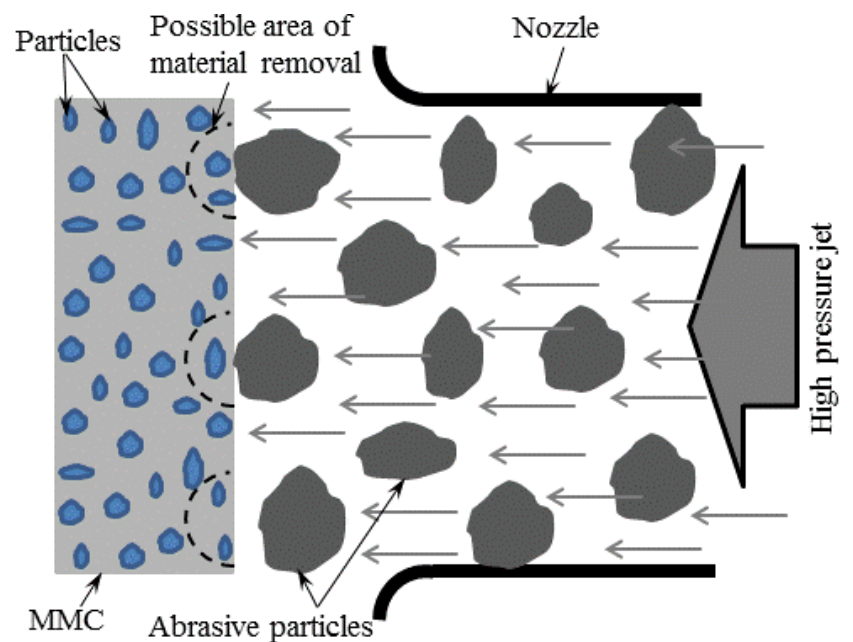

(a) Reinforcements smaller than abrasives

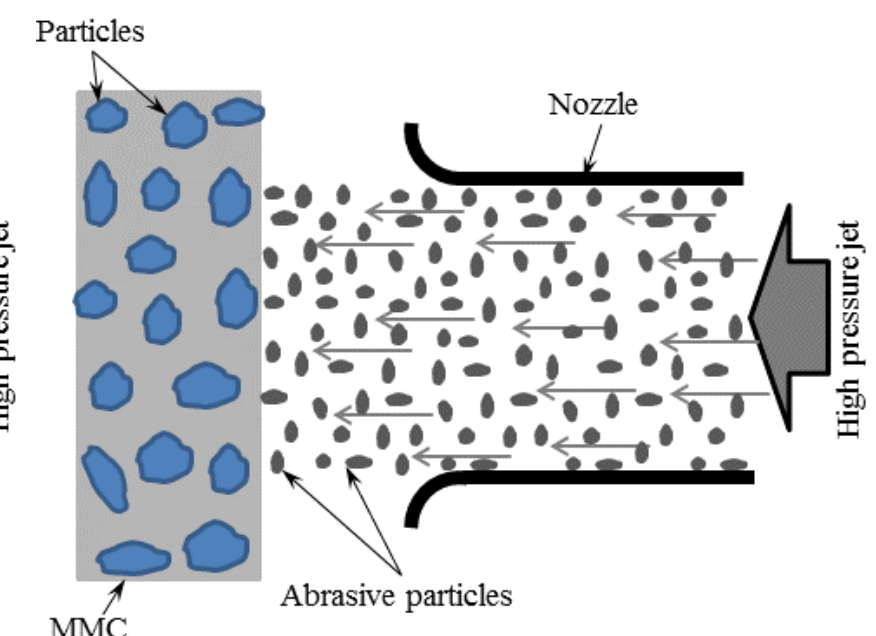

(b) Reinforcements bigger than abrasives

Fig. 20 Typical abrasive water jet machining mechanism

Three scenarios can be considered to explain the machining mechanism of MMC, such as (i) reinforcement particles in $\mathrm{MMC}$ are much smaller than abrasive particles in the water jet, (ii) reinforcement particles in MMC are very similar in size compare to the abrasive particles in the water jet and (iii) reinforcement particles in MMC are much larger than abrasive particles in the water jet. In case when the size of abrasive particle is bigger than the reinforcement particles (as in Fig. 20 (a)), an abrasive particle removes material which includes several reinforcement particles. In this case, there are chances of fracture and pull out of reinforced particles (Muller and Monaghan 2000) when those are partly in the matrix material and partly in the path of abrasive particles. In this case the effect of reinforcement particles on the surface finish is negligible compare to the effect of abrasive particles (Hashish 1995). With the decrease of the abrasive particle size it becomes unable remove a full reinforcement particle at a time when both particles have similar size. In this situation the abrasive particles push the reinforcements in the surface and over the surface which cause indentation and ploughing respectively. When the abrasive particles are very small as shown in Fig. 20 (b) the capacity to remove material for each abrasive particle is very little which is much smaller 
than the size of a reinforcement. Thus, the abrasive particles remove matrix as well as reinforcement materials progressively and smooth surfaces are generated (Hamatani and Ramulu 1990). The rate of reinforcement material removal is very slow compare to that of matrix material because of its high hardness. This produces smooth protrudes of reinforcement all over the matrix material surface. Savrun et al., (Savrun and Taya 1988) noted localised micro-melting in some areas of the matrix because of high speed $(400 \mathrm{~m} / \mathrm{sec})$ action of the abrasives ( 80 mesh) in the waterjet. Fig. 21 shows the micro-melting of matrix material of $25 \% \mathrm{SiCw} / \mathrm{A} 1$ after $\mathrm{AWJ}$ machining where the arrow in the picture shows the direction of machining.

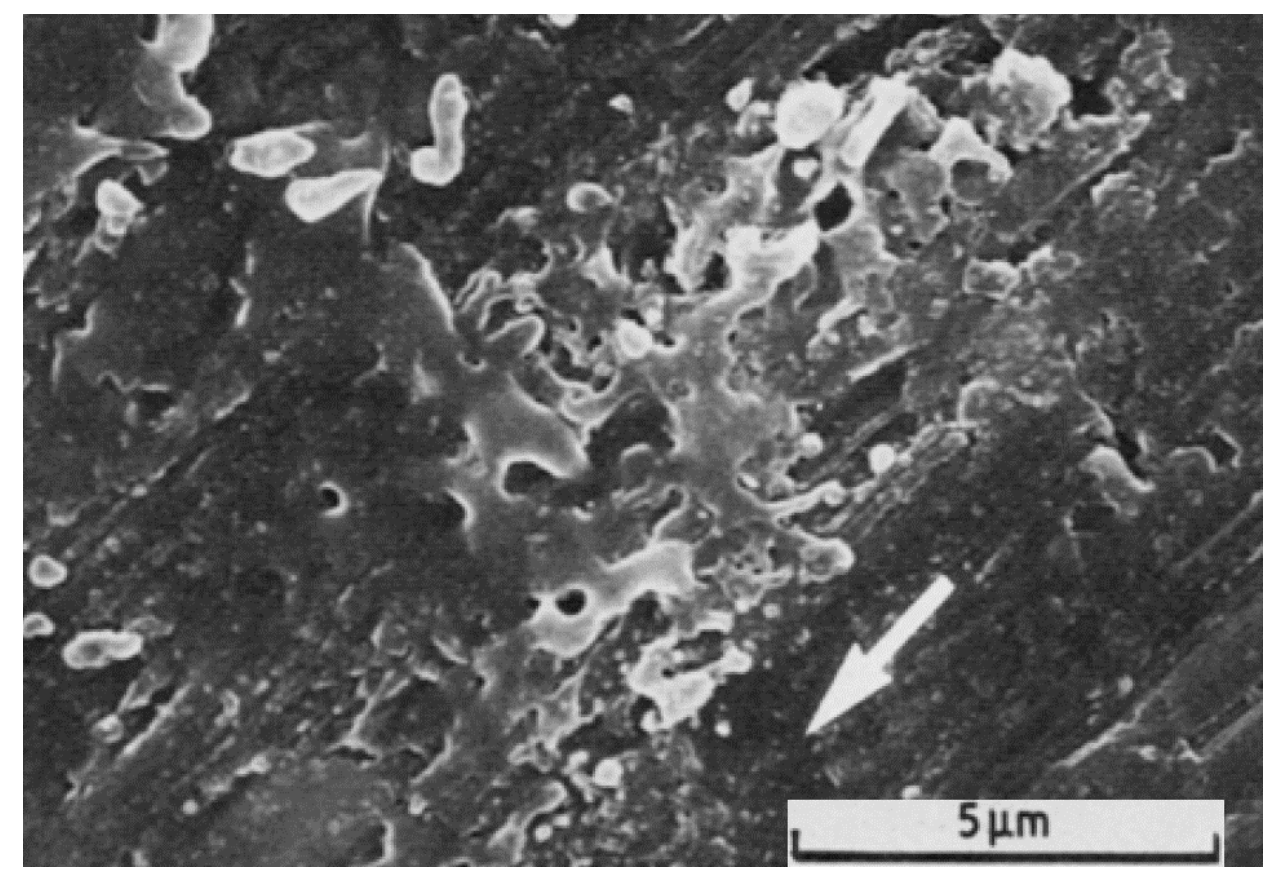

Fig. 21 Micro-melting of matrix material after AWJ machining at cutting speed $127 \mathrm{~mm} / \mathrm{min}$ (Savrun and Taya 1988)

\subsection{Cutting speed}

The cutting speed of water jet machining is also an input parameter. The time for material removal per unit area decreases with the increase of speed. Therefor at higher speed lower depth of cut will be achieved. In addition, surface roughness increases and striations become more visible at higher cutting speed (Savrun and Taya 1988).

\subsection{Surface finish and dimensional accuracy}

Generally rough surface is generated from AWJ machining (Hashish 1995; Capello, Polini et al. 1996; Muller and Monaghan 2000). However, the damage of subsurface is minimum in this process. 
No microstructural and microhardness changes occur in machined surfaces. The machined surface appears to be full of grooves where the abrasive particles embed in the metal matrix (Savrun and Taya 1988). A smoother surface can be obtained with lower cutting speed and depend on the size of abrasive particles used. Striation formation due to cutting lag and step removal is generally present when machining thicker MMC samples. The material removal process occurs mainly by cutting where the ductile shearing of the matrix material is observed from the abrasive scooping and ploughing path. Reinforcement particles in an MMC workpiece cut by AWJ are often pulled out from the matrix material if these are smaller than the abrasive particles (Muller and Monaghan 2000). Fig. 22 shows that the surface roughness obtained in MMC machined by AWJ increases with the increase of cutting speed. It also shows that the bigger abrasive particles produce rougher machined surface. It is interesting to note that when the particle size increase the rate of increase of surface roughness increases with the speed.

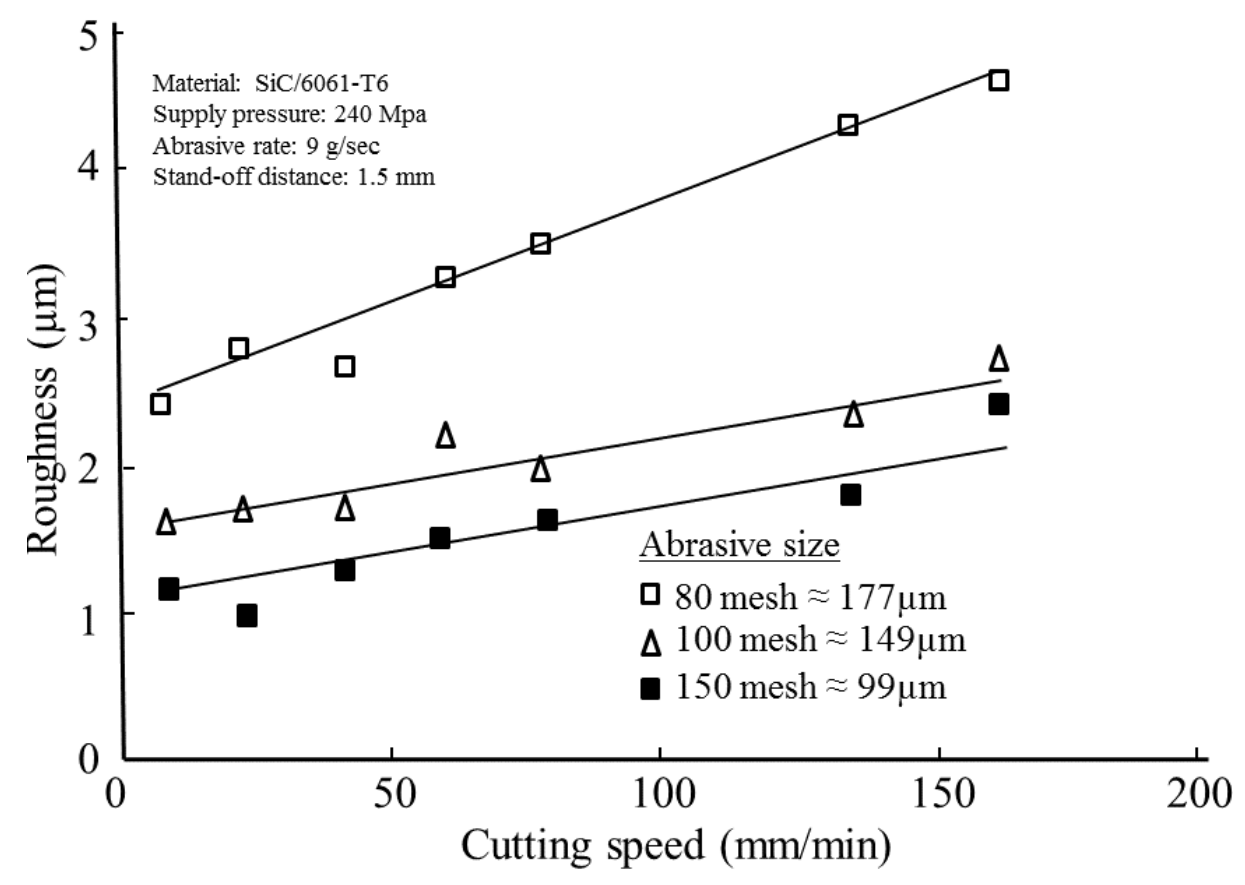

Fig. 22 Effect of cutting speed on the average surface roughness for different abrasive size (Hamatani and Ramulu 1990)

The effect of abrasive flow rate on the surface roughness of MMC machined by AWJ is given in Fig. 23. It shows that the higher flow rate of abrasive gives better surface finish at higher cutting speed. But a lower flow rate of abrasive gives better surface finish at lower cutting speed. It seems that optimum number of particles needs to take part at a time to remove material for obtaining the best surface finish. The effective number of particles takes part during machining at a time depends on the cutting speed and abrasive flow rate. Effective abrasive particles increase with the increase of flow 
rate and decrease of cutting speed. Thus surface roughness is expected to increase with the increase of cutting speed and decrease of abrasive flow rate. However, it seems that the abrasive particles become over crowded at low cutting speed when the flow rate of abrasive particles is higher. In this case the material removal becomes inefficient due to too much interaction among the particles. Therefore, surface roughness becomes worse at lower speed and higher flow rate of abrasive than that at lower speed and lower flow rate of abrasive.

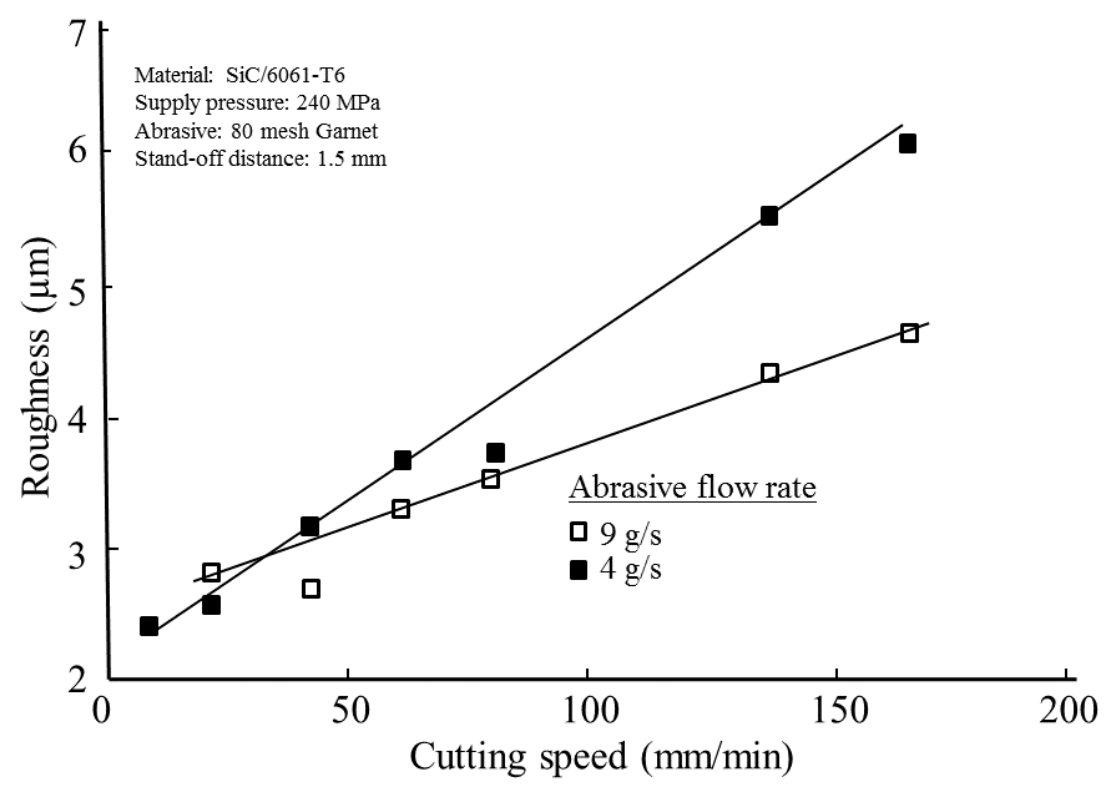

Fig. 23 Effect of cutting speed on the average surface roughness for different flow rate of abrasive (Hamatani and Ramulu 1990)

Hamatani and Ramulu (Hamatani and Ramulu 1990) used AWJ to produce single pass slot in SiC/6061-T6 MMC specimens at a constant water supply pressure using garnet abrasive. It was noted that the kerf taper ratio (ratio of top width to bottom width of the slot) depends on the cutting speed and abrasive size. Fig 24 shows that at lower speed the top width of the slot is always smaller than that of bottom width for the abrasive sizes considered. The difference between top and bottom widths of the slot reduces with the decrease of the abrasive particle size. With the increase of cutting speed the difference between top and bottom widths of the slot reduces. At a certain stage the top and bottom widths become equal at a critical speed, and then the top width starts to become bigger than the bottom width for all sizes of abrasives. The accuracy of AWJ machining can be depicted by the degree of taper and precision machining would require a cut with little or no taper. It appears an optimal cutting speed (critical speed) can be achieved for a given abrasive particle size and flow rate at which the machined slot is not tapered (Hamatani and Ramulu 1990). This critical speed at which the top and bottom widths become equal is different for different abrasive sizes. The critical speed 
increases with the increase of abrasive particle size (Fig 24). When the other parameters are constant, the increase of volume percentage of the reinforcement particles in MMC reduces the width of the bottom of the slot though the width of the top stays unchanged (Hashish 1995).

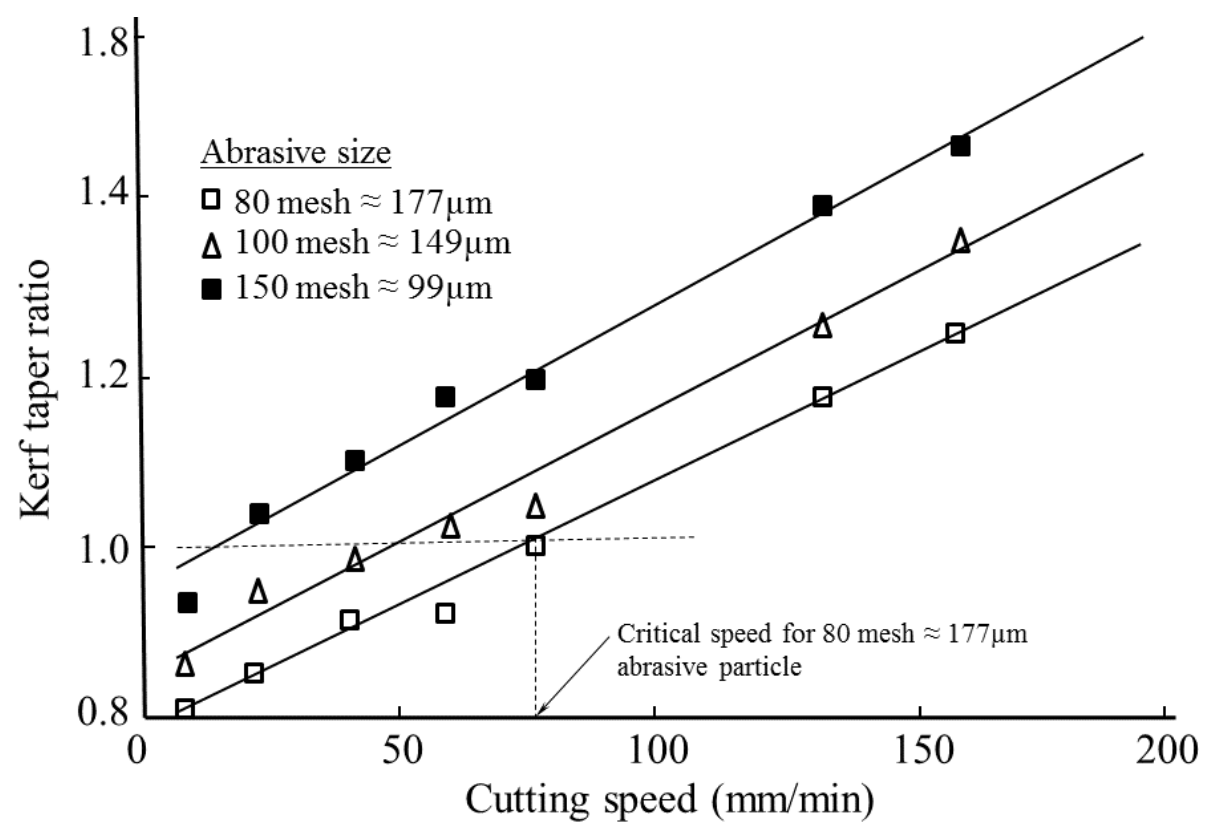

Fig. 24 Effect of cutting speed on the kerf taper ratio (ratio of top width to bottom width of the slot) for different abrasive size where abrasive flow rate is $9 \mathrm{~g} / \mathrm{sec}$ (Hamatani and Ramulu 1990)

Machining processes affect the surface finish in two ways (Hashish 1995), such as surface roughness and surface waviness. The surface roughness comes from the micro-effect of each impacting particles on the MMC and the surface waviness generates from the macro-effect of the interaction between AWJ and the workpiece. These depend on the properties of AWJ and MMCs.

\section{Electro-chemical machining}

In electrochemical machining (ECM), the material mainly metal (Senthilkumar, Ganesan et al. 2009) is removed by controlled electrochemical dissolution process of a workpiece (Kozak 1998) where workpiece and tool are anode and cathode respectively, and those are separated by an electrolyte. The ECM starts when an electric current is passed through the electrolyte. At this stage, the anodic workpiece dissolves locally and the shape of the removed material in workpiece is approximately a negative mirror image of that of the tool. The electrolyte is generally a concentrated salt solution. It is pumped through the machining gap at high velocity to remove the reaction products and to reduce heat generation (Bhattacharyya, Munda et al. 2004). Machining performance in ECM is controlled by the anodic behaviour of the workpiece material in a given electrolyte (Sorkhel and Bhattacharyya 1994). The ECM process is capable to manufacture complex shapes as well as miniature parts 
regardless of hardness of workpiece material (De Silva, Altena et al. 2000; Ebeid, Hewidy et al. 2004). In addition, there are several attractive advantages of electrochemical machining such as no burrs, no stress, a longer tool life, damage-free machined surface etc. (De Silva, Altena et al. 2000; Senthilkumar, Ganesan et al. 2009). This method has the capability to manufacture parts for the aerospace, automotive, defense, medical and electronics industries: for example turbine blades, engine castings, bearing cages, gears, dies and molds, artillery projectiles, surgical implants and micro-machining components (Datta 1998; Rajurkar, Zhu et al. 1999).

\subsection{Machining mechanism}

A voltage is applied while keeping the workpiece and tool at anodic and cathodic ends respectively in an electrolyte solution. Senthilkumar et al., (Senthilkumar, Ganesan et al. 2009) used copper with a square cross section as tool and fresh $\mathrm{NaCl}$ solution as electrolyte which was axially fed to the cutting zone through a central hole of the tool during machining SiC/Al MMC. Other electrolyte such as potassium nitrate, potassium chloride, sodium nitrate and sodium chloride can be used for ECM of metal matrix composites (Hihara 2000). During this process, the tool is advanced towards the workpiece in a defined path and the required shape of workpiece is achieved by using a suitable tool. Hihara (Hihara 2003) used calomel and aqueous sodium nitrate solution as cathode and electrolyte respectively. Dissolution occurred by the electrolytic removal of the matrix material, while the inert reinforced particles are flushed away by the electrolyte (Hihara 2000; Hihara 2003). Hihara (Hihara 2000) machined the MMC material and achieved tolerances of approximately 0.05 $\mathrm{mm}$ by maintaining small distances of approximately 0.025 to $0.75 \mathrm{~mm}$ between the material and the tool. Current density of equal to or greater than approximately $1 \mathrm{~A} / \mathrm{cm}^{2}$ was applied. The current density varied depending on the electrochemical machine used. Though current density in the range of 1 to $10 \mathrm{~A} / \mathrm{cm}^{2}$ was used current density of $2.5 \mathrm{~A} / \mathrm{cm}^{2}$ is preferred. The cavity generally conforms to shape of the cathode (i.e. tool). Electrochemical machining continues until the desired shape of the MMC material is formed (Hihara 2000).

During electrochemical machining, material removal rate increases with the increase of the applied voltage, feed, electrolyte concentration and flow rate. Increased voltage and electrolyte concentration result in a higher machining current in the inter-electrode gap. Increased feed also increases the current density due to the reduction in inter-electrode gap. At a higher electrolyte flow rate, ions from the metal to the solution are more mobile to speed up the chemical reactions, thus increases the metal removal rate (Senthilkumar, Ganesan et al. 2009). 
Unsteady and non-uniform metal dissolution leads to poor surface finish at a low voltage and feed. At a higher feed, however, pit formation takes place due to the higher current densities and the presence of particles (Hihara 2003). Excessive heating causes deterioration of the workpiece surface at a voltage above certain limit. At a lower electrolyte flow rate, the ions of material move slowly and produce streaks on the surface. Due to the depletion of ions, a poor surface finish is generated at a low electrolyte concentration (Senthilkumar, Ganesan et al. 2009).

The reinforcements do not significantly affect the breakdown potential of matrix materials. Hydrogen bubbles are produced during electro-chemical machining which impede dissolution and cause a nodular surface profile. The nodular profile can be eliminated by introducing rotational speeds at cathode and high electrolyte convection rates to flush away hydrogen bubbles. A very precise material removal can be made by accurately controlling the dissolution current and feed (Hihara 2003).

\subsection{Material removal rate}

Senthilkumar et al., (Senthilkumar, Ganesan et al. 2009) applied response surface methodology (RSM) and established relationship between various process parameters and material removal rate (MRR). The process parameters considered were: electrolyte concentration (g/lit), electrolyte flow rate (lit/min), applied voltage ( $\mathrm{v})$ and feed rate $(\mathrm{mm} / \mathrm{min})$. The effect of process parameters on the material removal rate during electrochemical machining of $\mathrm{MMC}(\mathrm{Al} / 10 \% \mathrm{SiC})$ is given in Fig. 25 where the lines with numbers presents different material removal rate (MRR) in $\mathrm{g} / \mathrm{min}$.

Fig. 25 (a) illustrates the influence of applied voltage and feed rate on MRR ( $\mathrm{g} / \mathrm{min})$. It shows that the material removal rate increases with the increase of applied voltage when the feed rate is constant. Similarly, MRR increases with the increase of feed rate when applied voltage is constant. The machining current increases in the inter-electrode gap with the increase of applied voltage. This results in higher MRR. The higher feed rate reduces the inter-electrode gap which increases the current density in the gap. This causes higher MMR by rapid anodic dissolution (Sen and Shan 2005). All these are fundamental principles of material removal in ECM. It is possible to maintain a constant MRR at different combinations of applied voltage and feed rate while other parameters are constant. Fig. 25(b) shows the effect of electrolyte concentration and flow rate on MRR. The increase of electrolyte concentration and flow rate increases the material removal rate while other parameters are constant. The number of ions in the inter-electrode gap increases at higher concentration of electrolyte which increases the conductivity and machining current, thus the material removal rate increases (Sen and Shan 2005). The faster flow rate of electrolyte increases the 
movement of the ions from the MMC to the solution. Thus hydrogen bubbles are removed more effectively, chemical reactions speed up and MRR increases (Rajurkar and Hewidy 1988; Neto, Silva et al. 2006). The variation of MRR with applied voltage and electrolyte flow rate is presented in Fig. 25(c). Increment of voltage and flow rate causes more metal removal rate. The reasons are already described above.

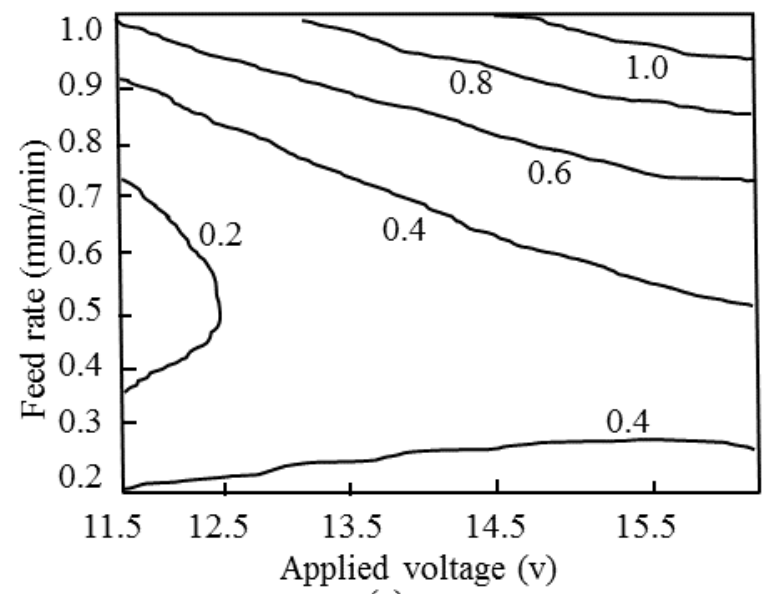

(a)

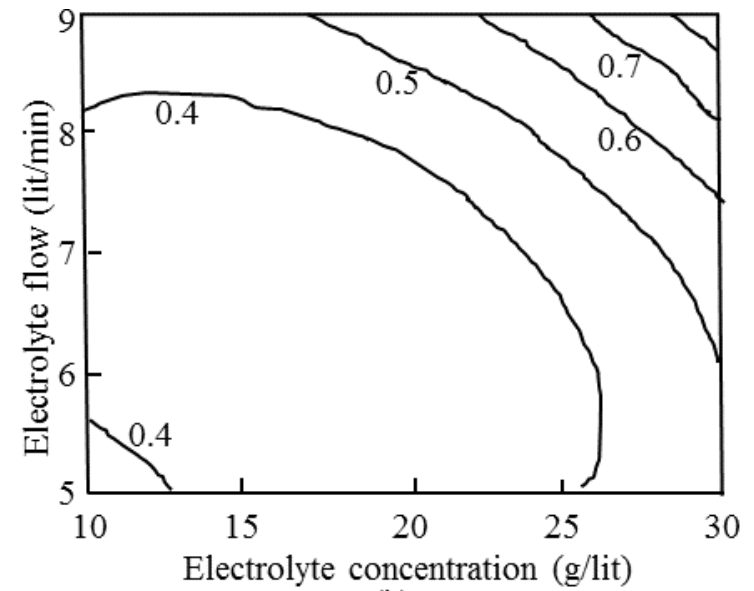

(b)

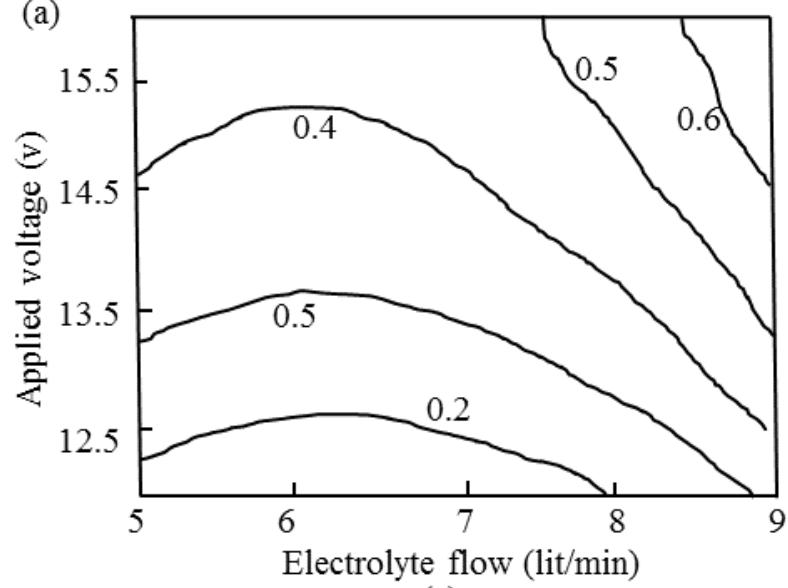

(c)

Fig. 25 Effect of process parameters on the material removal rate $(\mathrm{g} / \mathrm{min})$ during ECM of MMC (Senthilkumar, Ganesan et al. 2009)

\subsection{Surface finish}

The surface integrity of MMC during ECM process depends on the various process parameters, such as electrolyte flow rate, electrolyte concentration, applied voltage, and tool feed rate greatly influences the surface roughness characteristics. The various macro-defects produced on the machined surface by ECM are mainly due to the change in dissolution valency of the workpiece material during the course of machining operation (Senthilkumar, Ganesan et al. 2009). The effect of feed rate, electrolyte flow and electrolyte concentration on the surface finish of MMC surface after ECM is presented in Fig. 26. 


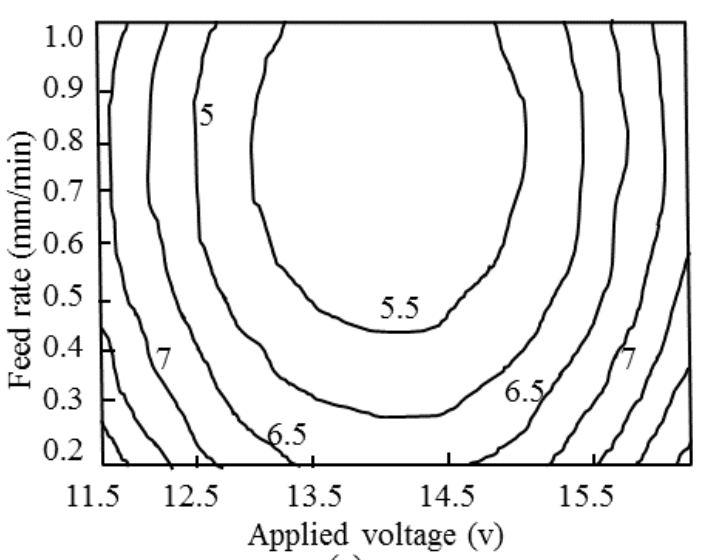

(a)

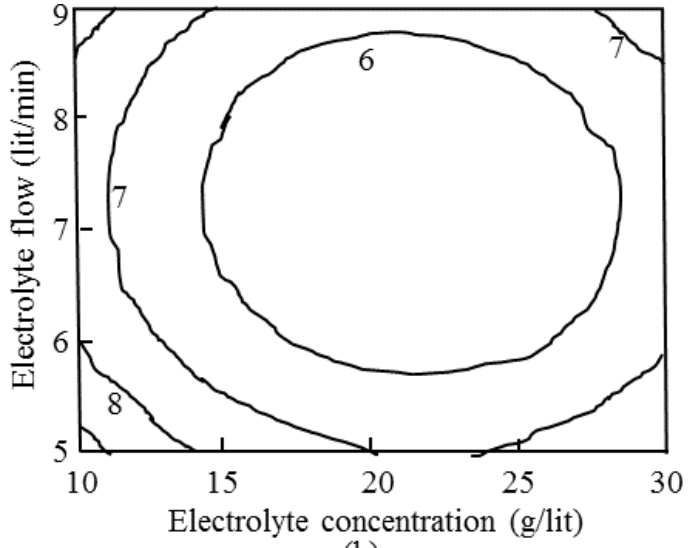

(b)

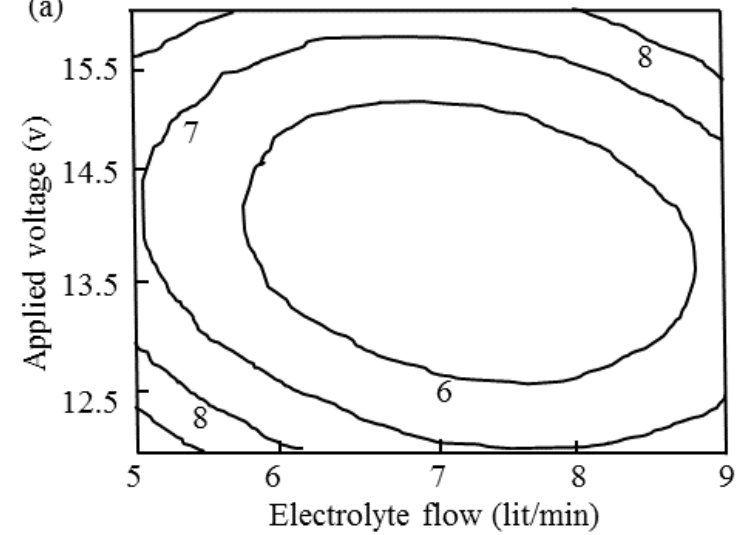

(c)

Fig. 26 Effect of process parameters on surface finish (Ra) rate during ECM of MMC (Senthilkumar, Ganesan et al. 2009)

Fig. 26(a) shows that at low voltage and feed rate surface roughness is higher. This is because of unsteady and non-uniform in anodic metal dissolution (Osman and Abdel-Rahman 1993). At low current density surface etchings reveals etch pits and preferred grain boundary is attacked which cause uneven microstructure leading to rougher surface. Fig. 27 shows pits on the machined surface due to low-current density (Senthilkumar, Ganesan et al. 2009). With the increase of voltage the current density in inter-electrode gape increases which improves the rate of metal ion deposition at the anode. Thin salt film starts to precipitate when the metal ion concentration exceeds certain limit. This salt film controls the surface morphology of a dissolved material. The limiting current which appears at high voltage suppresses surface defects on the dissolution process by thin salt film. Thus, better surface finish is produced at higher voltage (Sen and Shan 2005). The increase in feed rate tends to operate the process with smaller inter-electrode gap which increases the flow of current in the gap. In is already mentioned that the higher current density in the inter-electrode gap generates lower surface roughness (Sen and Shan 2005). Fig. 26(b) presents the effect of flow rate and electrolyte concentration on surface roughness. It shows that there is a critical flow rate and concentration until which the surface roughness decreases with the increase of these two parameters. 
But after that the surface roughness starts to increase. Turbulence in electrolyte becomes negligible when the flow rate is low. This causes slow movement of the diffused material in stratified form and generates streak on the machined surface. Ions shortage at low electrolyte concentration causes poor surface finish (Coughanowr, Dissaux et al. 1986). The current density increases with the increase of electrolyte concentration. This increases the tendency of pitting which is detrimental initially. However, if the formation of pits is raised an extent where a smooth surface can be achieved from the over lapping of many pits (Konig and Linderlauf 1978). The effect of applied voltage and flow rate on the surface roughness is given in Fig. 26(c). When the flow rate is constant the surface roughness decreases with the increase of voltage. However, after a certain limit of voltage, the roughness starts to increase with the increase of voltage. It seems that very high voltage causes excessive heating which worsen the machined surface increases the surface roughness (Senthilkumar, Ganesan et al. 2009). Similar to the applied voltage, initially the surface roughness decreases with the increase of flow rate but the surface roughness starts to increase after a certain limit of flow rate. Initially, as the flow rate increases, the turbulence becomes higher. Thus no flow streak appears on the surface results in better finish (Krishnaiah Chetty and Radhakrishnan 1981). However, with the further increase of flow rate the material removal becomes non-uniform which may cause worse surface finish

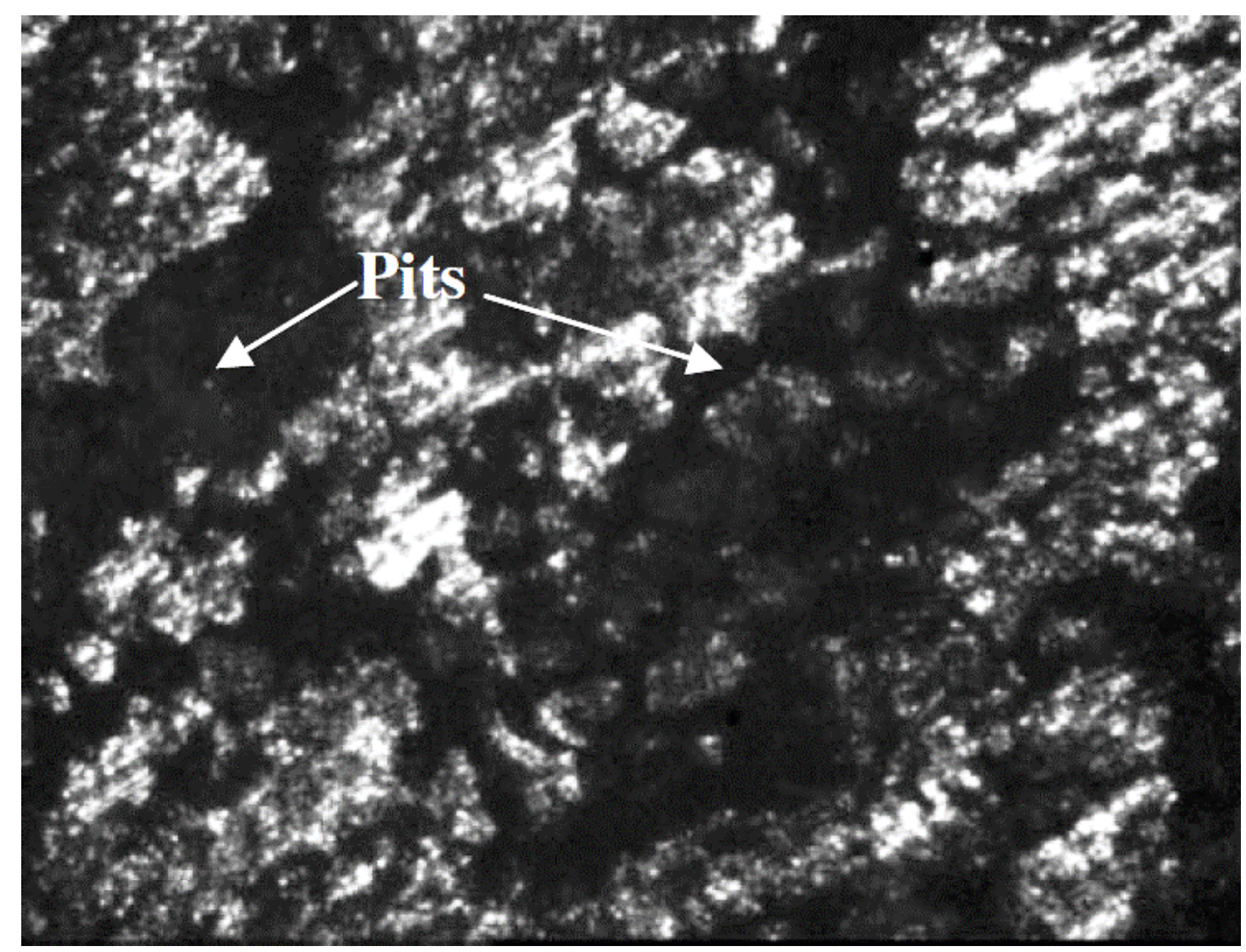

Fig. 27 Pits on the MMC surface after ECM at low voltage 12v (Senthilkumar, Ganesan et al. 2009) 


\section{Electro-chemical spark machining}

Electrochemical discharges spark machining (ECSM) is a hybrid process which combines the actions of electrical discharge machining (EDM) and electrochemical machining (ECM) (Liu 2011). This method has the capacity to machine electrically non-conductive materials like glass or some ceramics. This process is still a laboratory based method and yet to be applied in industries (Wüthrich and Fascio 2005). In this case, constant DC voltage or sometime pulsed voltage is applied between the tool-electrode (cathode) and the counter-electrode (anode) where both electrodes are dipped into the electrolyte and stay few centimetres apart typically. The surface area of counterelectrode is generally much larger than that of tool electrode (Wüthrich and Fascio 2005). Electrochemical discharges happen if the voltage is higher than a critical value which depends on the geometry and concentration of the electrolyte. At or above the critical voltage the production of gas bubble is very high and these coalesce into a gas film which isolates the tool electrode from the electrolyte. At this stage the electrical field in this film is very high and generates electrical discharges (Wüthrich and Fascio 2005) across these bubbles but not between electrodes (Abrate 1992). The heat from discharges and probably some chemical etching contribute to the eroding of the workpiece when it is positioned in the near vicinity of the electrode (Fascio, Wuthrich et al. 1999). The workpiece is held at a fixed distance from the anode and brought close to the cathode so that material removal could take place in the region where sparking occurs (Abrate 1992). This is the case when machining non-conductive materials. However, MMCs are conducting materials though non-conductive particles are reinforced into these materials. The machining mechanism of MMC is slightly different which has been discussed in the following section.

\subsection{Machining mechanism}

The material is removed by the complex physical-chemical actions where electro-chemical dissolution (ECD) as well as by electro-discharge erosion (EDE) take place simultaneously. Sodium nitrite $\left(\mathrm{NaNO}_{3}\right)$ and sodium hydroxide $(\mathrm{NaOH})$ are two commonly used electrolytes which provide limited conduction between the tool and the workpicce during machining of MMC. Fig. 28 presents a typical electro-chemical discharge machining of particle reinforced MMC. In this case, tool and workpiece electrodes act as cathode and anode respectively where a pulsed DC voltage is applied between the electrodes which lead to flow of current across the machining gap and, anodic dissolution of the workpiece takes place. The electro-chemical reactions also take place in the same time and increase the number of hydrogen bubbles at the cathode surface which increase the electrical resistance and voltage between the cathode and anode. When this voltage reaches a critical 
value the sparks are initiated. Thus, the electric discharge takes place between the tool and the MMC workpiece. The performance of ECDM depends on the machined surface, such as the form of the anodic surface film and the amount of gas evolution (Liu 2011).

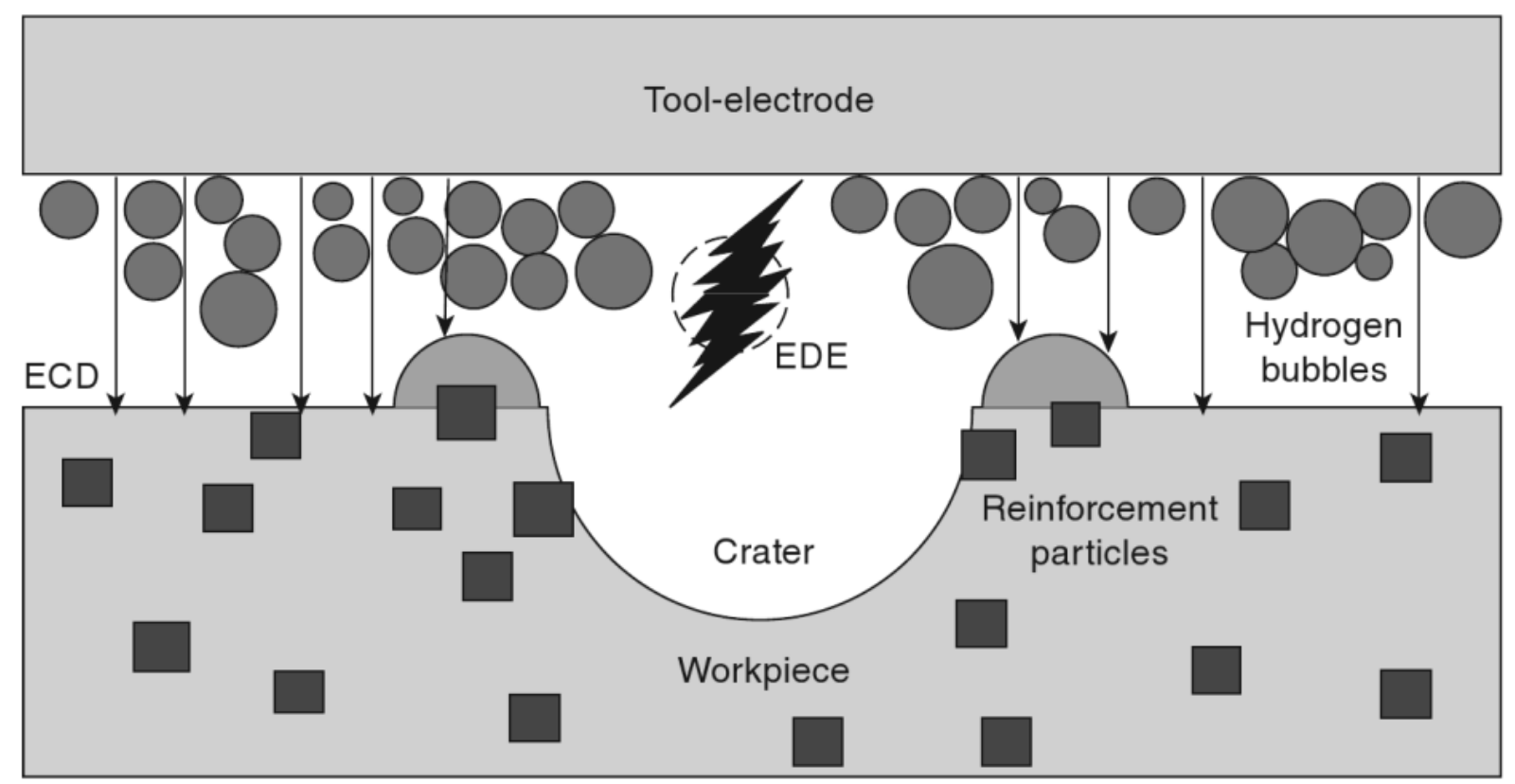

Fig. 28 Typical electro-chemical dissolution and electro-discharge erosion during ECDM (Liu 2011)

Higher current density is noted around the matrix-particle interfaces during ECDM of particulate MMC's which becomes prominent when the particle protrusion is less than $40 \%$ beyond which the intensity current density weakened. The higher current density at the interface boosts the chemical dissolution of the matrix material and the removal of the reinforced particles. Thus, ECM not only of dissolves the metal phase around the reinforcement phase but also actively enables sparking for EDM in a larger spark gap (Liu 2011). The larger electrode gap facilitates the removal of machined debris in this case. Liu et al., (Liu, Yue et al. 2010) revealed that the critical voltage for starting sparks does not depend on the presence of the reinforcement. The gas bubbles at the cathode surface may coalesce into a gas film which depends on electrolyte concentration, temperature and the geometry of the cathode electrode. A small cathode with a large anode-to-cathode surface ratio (typically over 100) is used during ECDM of non-conductors. This promotes the formation of a gas film (Liu 2011).

\subsection{Material removal rate}

The effects of pulse duration and reinforcement percentage on material removal rate of $\mathrm{A}_{2} \mathrm{O}_{3}$ reinforced aluminium MMCs composites are given in Fig. 29. It shows that the higher percentage of 
reinforcement reduce the material removal rate. This is due to higher protection of matrix material by ceramic reinforcement when percentage of reinforcement is higher. The material removal rate increases with the increase of pulse duration (16 $\mu$ s to $32 \mu \mathrm{s})$ initially but the material removal rate decreased with the further increase of pulse duration $(32 \mu \mathrm{s}$ to $64 \mu \mathrm{s})$.

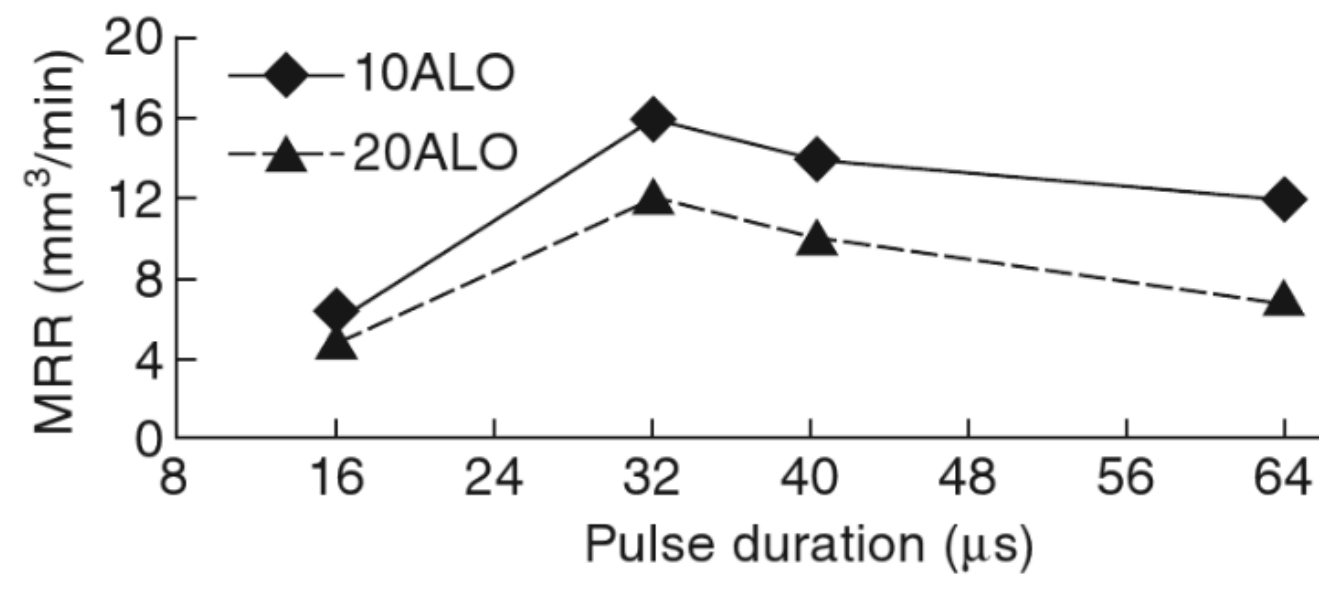

Fig. 29 Effects of pulse duration and reinforcement percentage on material removal rate

The initial increase of material removal rate with the increase of pulse duration is because of increased energy input. With the further increase of the pulse duration the energy put increase thus material removal further increases which clogs the ECDM process and material removal rate decreases as the debris (which comprises the reinforcing ceramic phase) trap within the spark gap and cannot be carried away quickly enough by the flushing fluid. It is likely that this phenomenon occurs when the reinforced particles are larger than the discharge gap. The machining process becomes unstable and material removal reduces if the number of the trapped particles is significant.

The effect of machining current on the material removal rate is presented in Fig. 30. It shows that material removal rate increases with the increase of current for both materials. As expected, the material removal rate for MMC with less percentage of reinforcement is higher in this case as well. The higher current facilitates ECD and increases the machining/electrode gap. This leads efficient removal of machined debris which facilitates stable. However, a further increase in spark gap beyond its optimal value leads to a decrease in MRR (Liu 2011). Thus there is an optimum gap-size above which the material removal rate decreases (Fig. 31). Similar to current the increase of applied voltage also increases the material removal rate which is shown in Fig. 32. Within the rage of the applied voltage in this figure a stable machining condition was maintained with efficient removal debris. Fig. 33 shows the effect of electrolyte concentration on the material removal rate of MMCs. It shows that there is an optimum electrolyte concentration for which highest material removal can be achieved. 
When the concentration of electrolyte is low the rate hydrogen formation at the cathode is low which delays enough bubbles formation and achieving the critical voltage for EDE. Thus production of molten material reduces. Though ECD effect is enhanced in high concentrated electrolyte the EDE reduces which results in lower material removal rate.

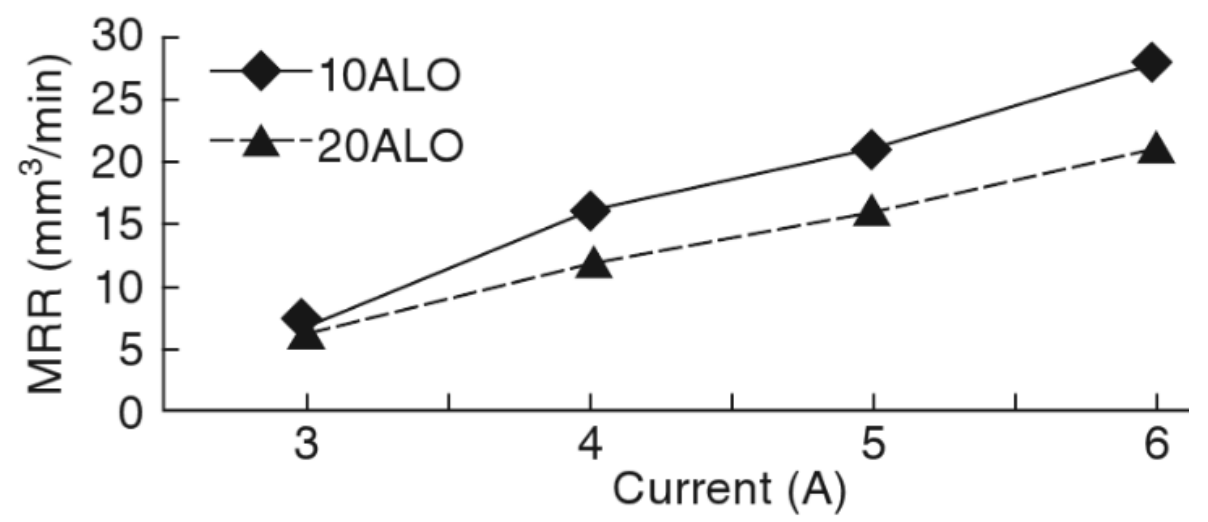

Fig. 30 The effect of machining current on the material removal rate (Liu 2011)

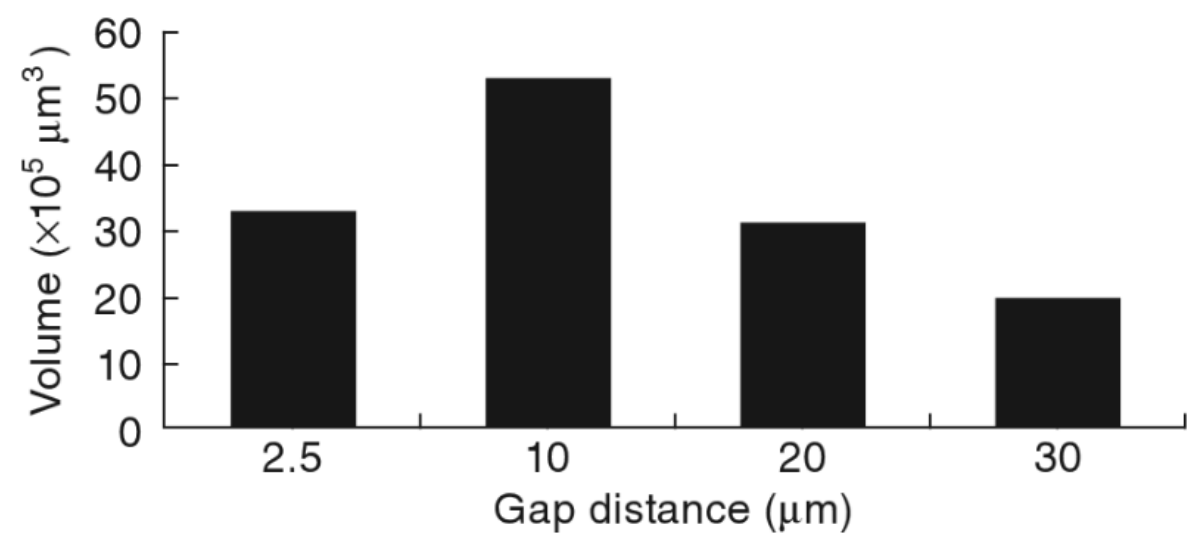

Fig. 31 Effect of gap size on the material removal rate under single pulse condition (Liu 2011)

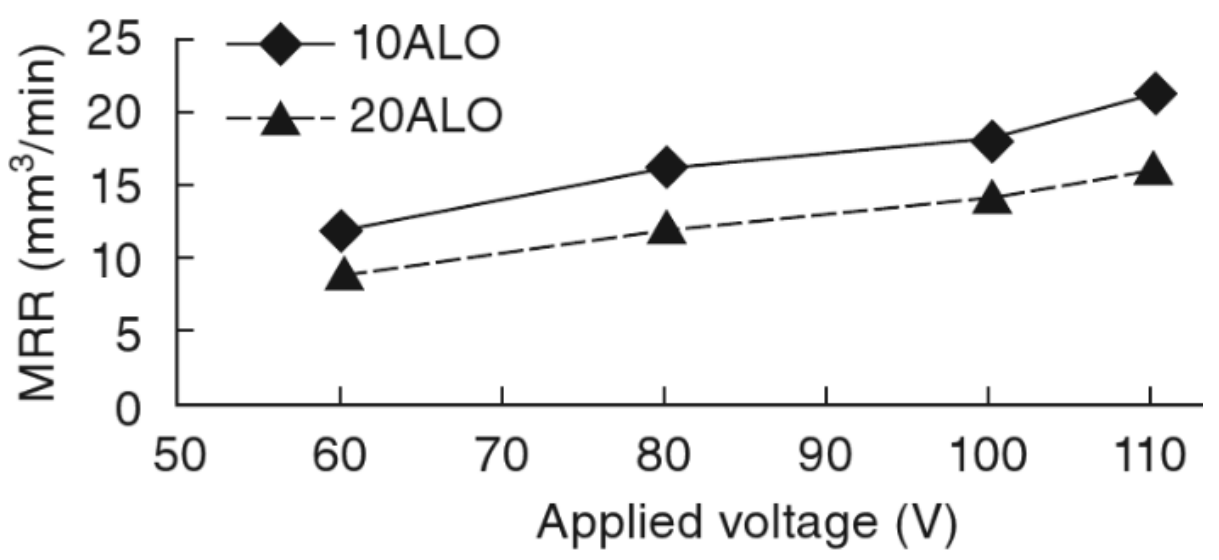

Fig. 32 Effect of voltage on the material removal rate where pulse duration $32 \mu$ s, electrolyte concentration $0.5 \mathrm{wt} \%$ and current $4 \mathrm{~A}$ (Liu 2011) 


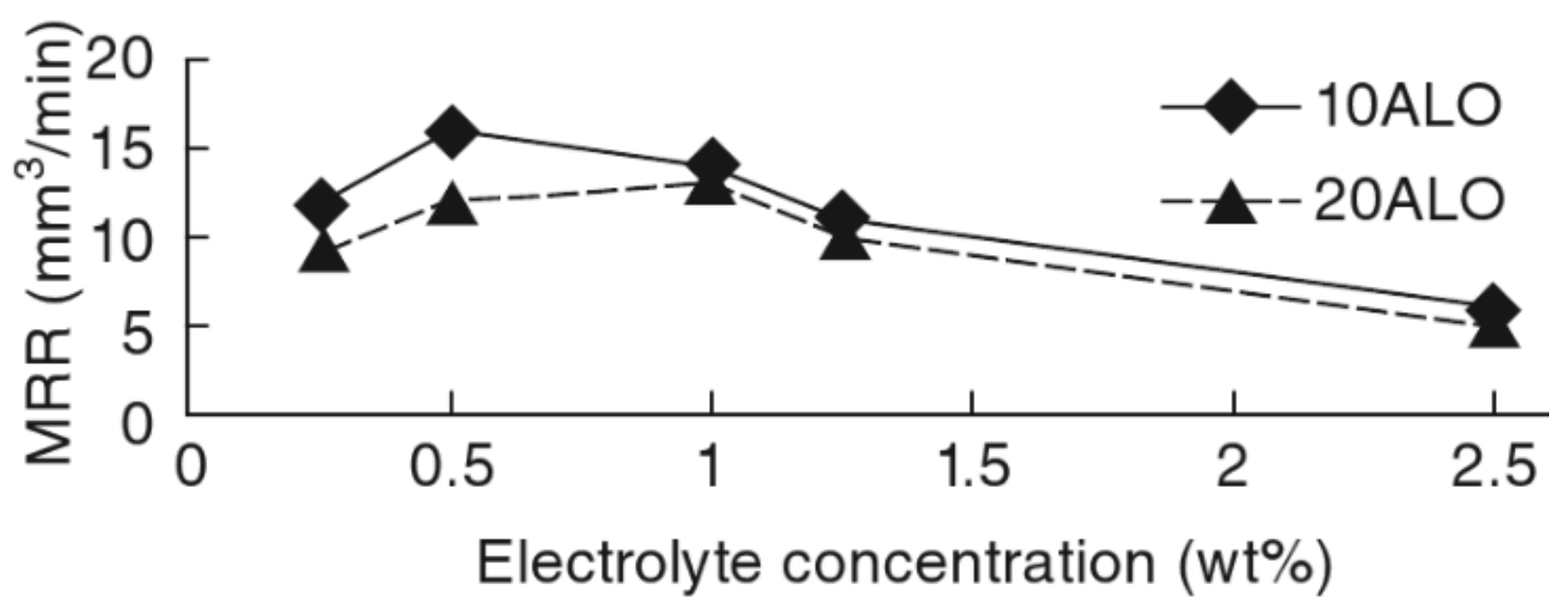

Fig. 33 Effect of electrolyte concentration on the material removal rate (Liu 2011)

\subsection{Surface finish}

Fig. 34 presents the effect of pulse duration and content of reinforcement on the surface roughness (Ra) of $\mathrm{A}_{2} \mathrm{O}_{3}$ reinforced $\mathrm{Al}$ MMCs. It shows that the surface roughness initially decreases with the increase of pulse duration but it starts to increase at a lower rate with further increase of pulse duration. The increase of pulse duration increases EDE and ECD activities, particularly the EDE activity that was strong at duration of $32 \mu \mathrm{m}$. The increase in pulse duration increases amount of hydrogen bubbles which increases the voltage between the two electrodes and causes EDE. In case of shorter $(16 \mu \mathrm{s})$ pulse duration, the material removal takes place only by ECM. The surface roughness increases without EDE as the reinforcements are exposed on the machined surfaces which were not removed by ECD alone. Thus, the surface roughness is increased significantly due to protrude of particles at the surface. The effect of current and electrolyte concentration on surface roughness of different MMCs are shown in Figs. 35 and 36, respectively. The surface roughness of the both composites increases slightly with the increase of current. An increase in current will result in a higher pulse energy, which means larger discharge craters will form and thus increase the surface roughness. Fig. 35 shows that the roughness increases sharply when the concentration of electrolyte becomes more than a certain limit (in this case $1.25 \mathrm{wt} \%$ ). This is also may be due to the lack of EDE and the domination of ECD at higher concentration of electrolyte. 


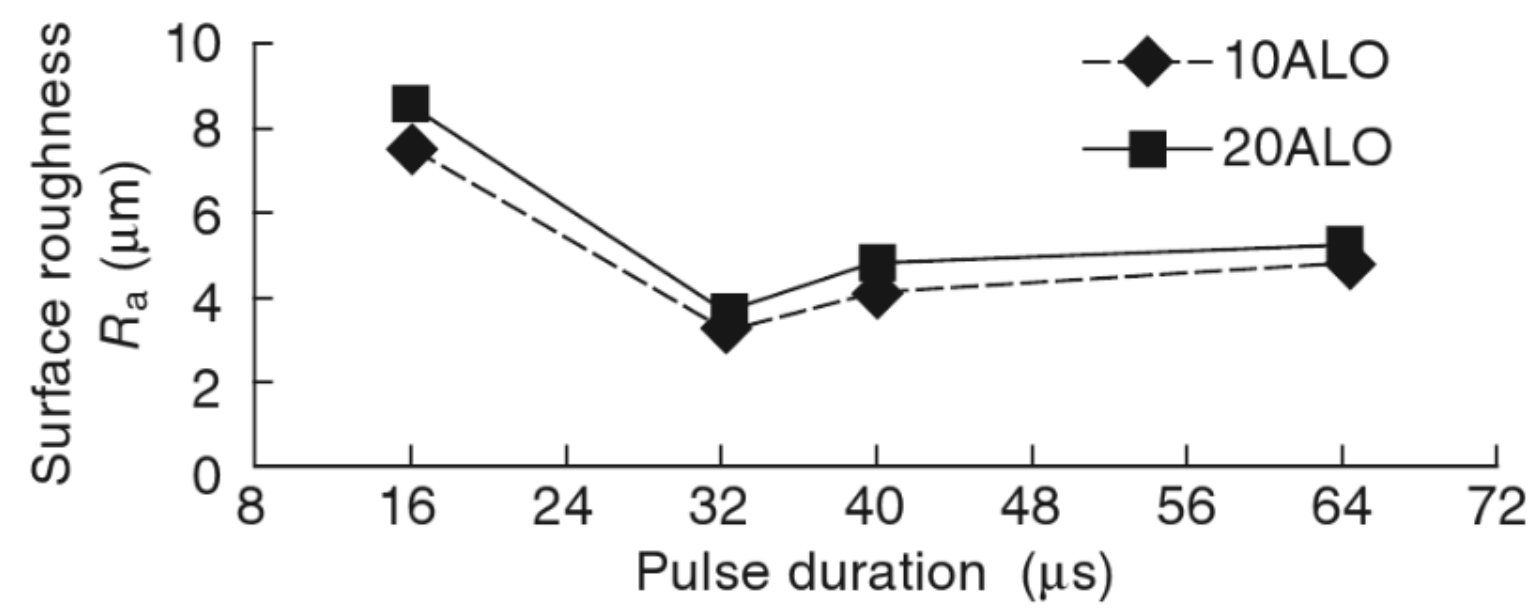

Fig. 34 The effect of pulse duration and content of reinforcement on the surface roughness (Liu 2011)

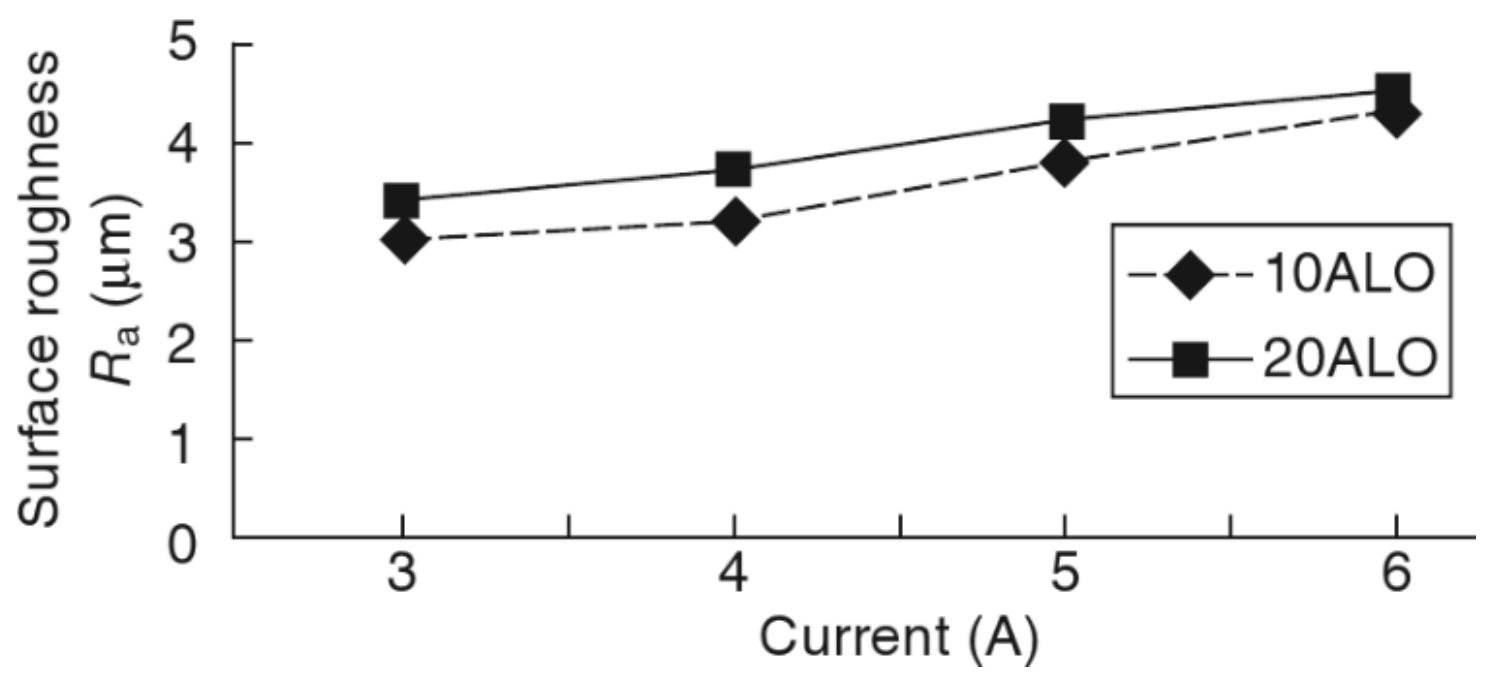

Fig. 35 Effect of current on the surface roughness of different MMCs (Liu 2011)

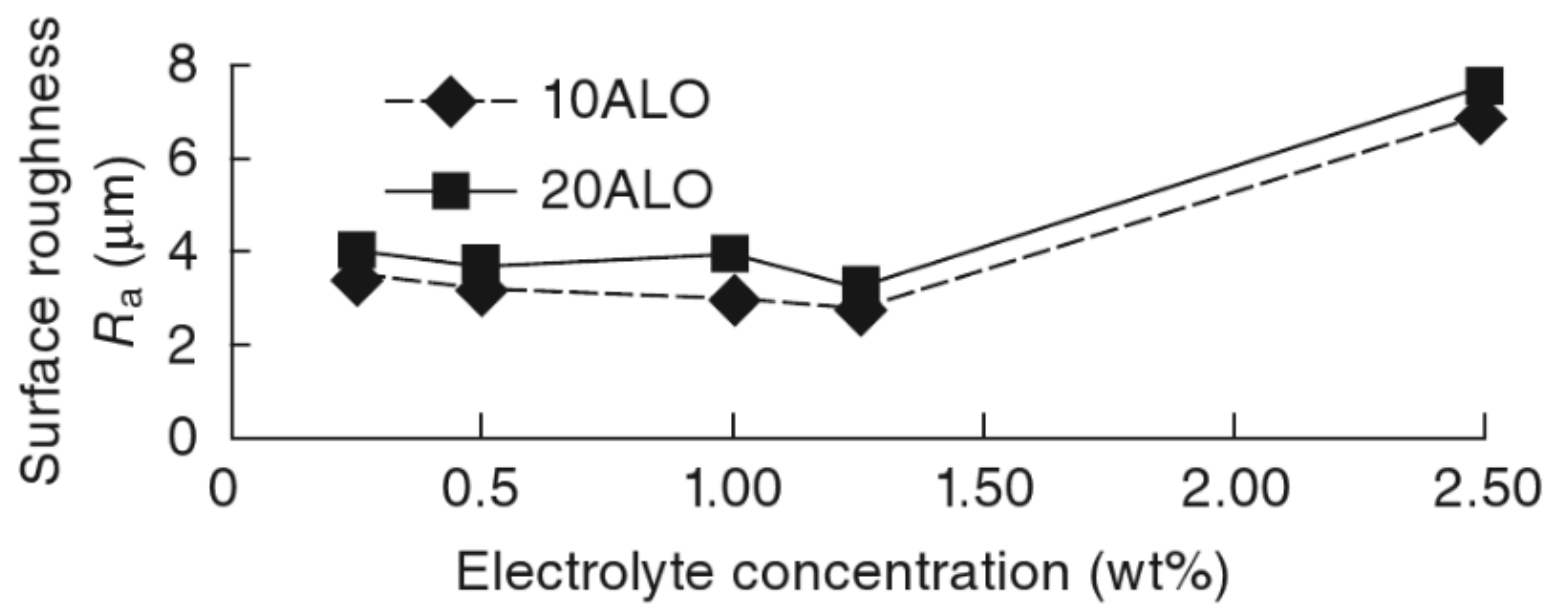

Fig. 36 Effect of electrolyte concentration on surface roughness of different MMCs (Liu 2011) 


\section{Conclusion}

Research in non-traditional machining of particulate reinforced MMCs is still developing though it has made good progress in few areas. The presence of reinforced particles adds additional complexity and makes the machining process different than that of monolithic matrix material. Most of the processes have different abilities of removing reinforced particles and matrix material. Thus there are still deficiencies in understanding the mechanisms of most the machining processes. Tool wear, tool breaking and recast layer are the main problems in electro-discharge machining. Excessive heating in laser cutting evaporates and melts the matrix material as well as reinforced particles which also initiate chemical reaction and changes material composition during the laser-beam machining. Striation pattern and dross attachment on the machined surface are common problems in this case. Materials are removed by mechanical erosion during abrasive water jet machining. The surface finish of the machined surface depends on the relative size of reinforced and abrasive particles. Inaccuracy is the main problem in abrasive jet machining. Electro-chemical and electro-chemical discharge machining are the least know process for machining particulate reinforced metal matrix composite. Matrix materials around inert reinforced particles dissolve chemically and flashed away during electrochemical machining. It is slow process and production of hydrogen gas at the cathode further slows down the process. Electro-chemical discharge machining is hybrid process which combines the effects of electro-chemical machining and electro-discharge machining. It is quit fast process but the surface finish is comparatively bad. It seems that in-depth investigations in unconventional machining may bring about promising results in processing of MMCs as these processes have some mentionable advantages over conventional machining processes.

\section{References}

Abrate, S., Walton, D. (1992). "Machining of composite materials. Part II: Non-traditional methods." Composites Manufacturing 3(2): 85-94.

Bhattacharyya, B., J. Munda, et al. (2004). "Advancement in electrochemical micro-machining." International Journal of Machine Tools and Manufacture 44(15): 1577-1589.

Capello, E., W. Polini, et al. (1996). Abrasive water jet cutting of MMC: Analysis of the quality of the generated surfaces. Proceedings of the ESDA conference, ASME, New York, PD.

Coughanowr, C. A., B. A. Dissaux, et al. (1986). "Electrochemical machining of refractory materials." Journal of applied electrochemistry 16(3): 345-356. 
Dahotre, N. B., T. D. McCay, et al. (1989). "Laser processing of a SiC/Al-alloy metal matrix composite." Journal of Applied Physics 65(12): 5072-5077.

Datta, M. (1998). "Microfabrication by electrochemical metal removal." IBM Journal of Research and Development 42(5): 655-669.

De Garmo, E. P., Black, J. T., \& Kohser, R. A. (2011). "DeGarmo's materials and processes in manufacturing." John Wiley \& Sons.

De Silva, A. K. M., H. S. J. Altena, et al. (2000). "Precision ECM by Process Characteristic Modelling." CIRP Annals - Manufacturing Technology 49(1): 151-155.

Di Pietro, P. and Y. L. Yao (1995). "A new technique to characterize and predict laser cut striations." International Journal of Machine Tools and Manufacture 35(7): 993-1002.

Dubey, A. K. and V. Yadava (2008). "Laser beam machining-A review." International Journal of Machine Tools and Manufacture 48(6): 609-628.

Ebeid, S., M. Hewidy, et al. (2004). "Towards higher accuracy for ECM hybridized with lowfrequency vibrations using the response surface methodology." Journal of Materials Processing Technology 149(1): 432-438.

Fascio, V., R. Wuthrich, et al. (1999). 3D microstructuring of glass using electrochemical discharge machining (ECDM). Micromechatronics and Human Science, 1999. MHS '99. Proceedings of 1999 International Symposium on.

Gatto, A. and L. Iuliano (1997). "Cutting mechanisms and surface features of WED machined metal matrix composites." Journal of Materials Processing Technology 65(1-3): 209-214.

Hamatani, G. and M. Ramulu (1990). "Machinability of high temperature composites by abrasive waterjet." Journal of Engineering Materials and Technology 112(4): 381-386.

Hashish, M. (1995). "Waterjet machining of advanced composites." MATERIAL AND MANUFACTURING PROCESS 10(6): 1129-1152.

Hihara, L. H., Panquites, P. (2000). "Method of electrochemical machining (ECM) of particulate metal-matrix composites (MMCs)." U.S. Patent No. 6,110,351. Washington, DC: U.S. Patent and $\underline{\text { Trademark Office. }}$

Hihara, L. H. P., P. (2003). "The potential of electrochemical machining for silicon carbide/aluminum metal-matrix composites." Abrasives and Grinding Magazine Dec-Jan: 12-17. 
Ho, K. H. and S. T. Newman (2003). "State of the art electrical discharge machining (EDM)." International Journal of Machine Tools and Manufacture 43(13): 1287-1300.

Hocheng, H., W. T. Lei, et al. (1997). "Preliminary study of material removal in electrical-discharge machining of SiC/Al." Journal of Materials Processing Technology 63(1-3): 813-818.

Hong, L., R. Vilar, et al. (1997). "Laser beam processing of a SiC particulate reinforced 6061 aluminium metal matrix composite." Journal of Materials Science 32(20): 5545-5550.

Hu, C. and T. N. Baker (1997). "A new aluminium silicon carbide formed in laser processing." Journal of Materials Science 32(19): 5047-5051.

Hung, N. P., L. J. Yang, et al. (1994). "Electrical discharge machining of cast metal matrix composites." Journal of Materials Processing Technology 44(3-4): 229-236.

Kagawa, Y., S. Utsunomiya, et al. (1989). "Laser cutting of CVD-SiC fibre/A6061 composite." Journal of materials science letters 8(6): 681-683.

Kirk, D. (visited on 6th March 2014). "quick and easy formula for mesh-micron particle size conversions." $\quad$ CSC $\quad$ Publishing, Powder and Bulk Engineering http://www.powderbulk.com/Content/viewRequest.aspx?ID=ba022613-4793-4e71-b510$\underline{\text { f92867906637\&fi=1. }}$.

Konig, W. and P. Linderlauf (1978). "Surface generation in electrochemical machining." Annals of the CIRP 27(1): 97-100.

Kovacevic, R., M. Hashish, et al. (1997). "State of the art of research and development in abrasive waterjet machining." Journal of manufacturing science and engineering 119(4B): 776-785.

Kozak, J. (1998). "Mathematical models for computer simulation of electrochemical machining processes." Journal of Materials Processing Technology 76(1-3): 170-175.

Krishnaiah Chetty, O. V. and V. Radhakrishnan (1981). "A study on the influence of grain size in electrochemical machining." International Journal of Machine Tool Design and Research 21(1): 5769.

Lau, W. S., T. M. Yue, et al. (1994). "Ultrasonic-Aided Laser Drilling of Aluminium-Based Metal Matrix Composites." CIRP Annals - Manufacturing Technology 43(1): 177-180. 
Liao, Y. S., Y. Y. Chu, et al. (1997). "Study of wire breaking process and monitoring of WEDM." International Journal of Machine Tools and Manufacture 37(4): 555-567.

Liu, J. (2011). "Electrochemical discharge machining of particulate reinforced metal matrix composites." Machining Technology for Composite Materials: Principles And Practice: 242.

Liu, J., T. Yue, et al. (2010). "An analysis of the discharge mechanism in electrochemical discharge machining of particulate reinforced metal matrix composites." International Journal of Machine Tools and Manufacture 50(1): 86-96.

Mohan, B., A. Rajadurai, et al. (2002). "Effect of SiC and rotation of electrode on electric discharge machining of Al-SiC composite." Journal of Materials Processing Technology 124(3): 297-304.

Mohan, B., A. Rajadurai, et al. (2004). "Electric discharge machining of Al-SiC metal matrix composites using rotary tube electrode." Journal of Materials Processing Technology 153: 978-985.

Muller, F. and J. Monaghan (2000). "Non-conventional machining of particle reinforced metal matrix composite." International Journal of Machine Tools \& Manufacture 40(9): 1351-1366.

Muller, F. and J. Monaghan (2001). "Non-conventional machining of particle reinforced metal matrix composites." Journal of Materials Processing Technology 118(1-3): 278-285.

Neto, J. C. d. S., E. M. d. Silva, et al. (2006). "Intervening variables in electrochemical machining." Journal of Materials Processing Technology 179(1-3): 92-96.

Osman, H. M. and M. Abdel-Rahman (1993). "Integrity of surfaces produced by electrochemical machining." Journal of Materials Processing Technology 37(1-4): 667-677.

Pham, D. T., S. S. Dimov, et al. (2007). "Laser milling of ceramic components." International Journal of Machine Tools and Manufacture 47(3-4): 618-626.

Pramanik, A., L. C. Zhang, et al. (2006). "Prediction of cutting forces in machining of metal matrix composites." International Journal of Machine Tools and Manufacture 46(14): 1795-1803.

Pramanik, A., L. C. Zhang, et al. (2007). "An FEM investigation into the behavior of metal matrix composites: Tool-particle interaction during orthogonal cutting." International Journal of Machine Tools and Manufacture 47(10): 1497-1506.

Rajurkar, K. P. and M. S. Hewidy (1988). "Effect of grain size on ECM performance." Journal of Mechanical Working Technology 17(0): 315-324. 
Rajurkar, K. P., D. Zhu, et al. (1999). "New Developments in Electro-Chemical Machining." CIRP Annals - Manufacturing Technology 48(2): 567-579.

Ramulu, M. and D. Arola (1993). "Water jet and abrasive water jet cutting of unidirectional graphite/epoxy composite." Composites 24(4): 299-308.

Ramulu, M., P. N. Rao, et al. (2002). "Drilling of (Al2O3)p/6061 metal matrix composites." Journal of Materials Processing Technology 124(1-2): 244-254.

Ramulu, M. and M. Taya (1989). "EDM MACHINABILITY OF SICW/AL COMPOSITES." Journal of Materials Science 24(3): 1103-1108.

Rozenek, M., J. Kozak, et al. (2001). "Electrical discharge machining characteristics of metal matrix composites." Journal of Materials Processing Technology 109(3): 367-370.

Savrun, E. and M. Taya (1988). "Surface characterization of SiC whisker/2124 aluminium and Al2O3 composites machined by abrasive water jet." Journal of Materials Science 23(4): 1453-1458.

Sen, M. and H. S. Shan (2005). "Analysis of hole quality characteristics in the electro jet drilling process." International Journal of Machine Tools and Manufacture 45(15): 1706-1716.

Senthilkumar, C., G. Ganesan, et al. (2009). "Study of electrochemical machining characteristics of $\mathrm{Al} / \mathrm{SiCp}$ composites." The International Journal of Advanced Manufacturing Technology 43(3-4): 256-263.

Shanmugam, D., F. Chen, et al. (2002). "Comparative study of jetting machining technologies over laser machining technology for cutting composite materials." Composite Structures 57(1): 289-296.

Singh, P. N., K. Raghukandan, et al. (2004). "Electric discharge machining of Al-10\%SiCp as-cast metal matrix composites." Journal of Materials Processing Technology 155: 1653-1657.

Sorkhel, S. K. and B. Bhattacharyya (1994). "Parametric control for optimal quality of the workpiece surface in ECM." Journal of Materials Processing Tech. 40(3-4): 271-286.

Wang, C. C. and B. H. Yan (2000). "Blind-hole drilling of Al2O3/6061Al composite using rotary electro-discharge machining." Journal of Materials Processing Technology 102(1-3): 90-102.

Wang, J. (1999). "Abrasive waterjet machining of polymer matrix composites-cutting performance, erosive process and predictive models." The International Journal of Advanced Manufacturing Technology 15(10): 757-768. 
Wüthrich, R. and V. Fascio (2005). "Machining of non-conducting materials using electrochemical discharge phenomenon - an overview." International Journal of Machine Tools and Manufacture 45(9): 1095-1108.

Yan, B. H., H. C. Tsai, et al. (2005). "Examination of wire electrical discharge machining of $\mathrm{Al}(2) \mathrm{O}(3) \mathrm{p} / 6061 \mathrm{Al}$ composites." International Journal of Machine Tools \& Manufacture 45(3): 251259.

Yan, B. H. and C. C. Wang (1999). "The machining characteristics of Al2O3/6061Al composite using rotary electro-discharge machining with a tube electrode." Journal of Materials Processing Technology 95(1-3): 222-231.

Yue, T. M., Y. Dai, et al. (1996). "An Examination of Wire Electrical Discharge Machining (WEDM) of Al2O3 Particulate Reinforced Aluminum Based Composites." Materials and Manufacturing Processes 11(3): 341-350.

Yue, T. M. and W. S. Lau (1996). "Pulsed Nd:YAG Laser Cutting of Al/Li/SiC Metal Matrix Composites." Materials and Manufacturing Processes 11(1): 17-29. 
$31^{\text {st }}$ March 2014

Department of Mechanical Engineering

Curtin University

GPO Box U1987

Perth, WA 6845

Phone: +61 892667981

Fax: +61 892662681

E-mail: alokesh.pramanik@curtin.edu.au

Prof T.A. Dean

Editor-in-Chief

International Journal of Machine Tools and Manufacture

Dear Prof Dean,

We would be grateful if you could consider the enclosed paper titled "Developments in the non-traditional machining of particle reinforced metal matrix composites" for publication in International Journal of Machine Tools and Manufacture. The article is original and never published or not submitted anywhere for publication.

I look forward to hearing from you in due course.

Thank you very much.

Sincerely yours,

Dr Alokesh Pramanik 


\title{
Developments in the non-traditional machining of particle reinforced metal matrix composites
}

\author{
A. Pramanik
}

(Email: alokesh.pramanik@curtin.edu.au, Phone: +61 89266 7981)

Department of Mechanical Engineering, Curtin University, Bentley, WA, Australia

\begin{abstract}
The non-traditional machining of particulate reinforced metal matrix composites is relatively new. However, researchers seem to pay more attention in this field recently as the traditional machining of particulate reinforced metal matrix composites is very complex. This research investigates different non-traditional machining, such as electro-discharge, laser beam, abrasive water jet, electro-chemical and electro-chemical discharge machining of this composite materials. The machining mechanism, material removal rate/machining speed and surface finish have been analysed for every machining process. This analysis clearly shows that vaporisation, melting, chemical dissolution and mechanical erosion are the main material removal mechanism during non-traditional machining. The thermal degradation and presence of reinforcement particles mainly damage the machined surface. The understanding on electro-discharge, laser beam and abrasive water jet machining are more developed than that of electro-chemical and electro-chemical discharge machining for particulate reinforced MMC.
\end{abstract}

Key words: Particle reinforced metal matrix composites, non-traditional machining, material removal rate, surface finish, machining mechanism. 